volume 7

ISSUE 2

2019 marzo-aprile

Editor in Chief Paola Gnerre

Supervisor Editor Roberto Nardi

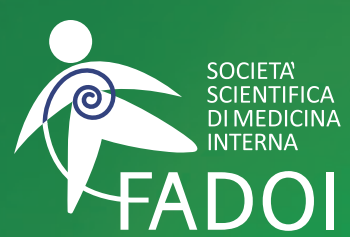

FEDERAZIONE

DELLE ASSOCIAZIONI

DEI DIRIGENTI

OSPEDALIERI

INTERNISTI

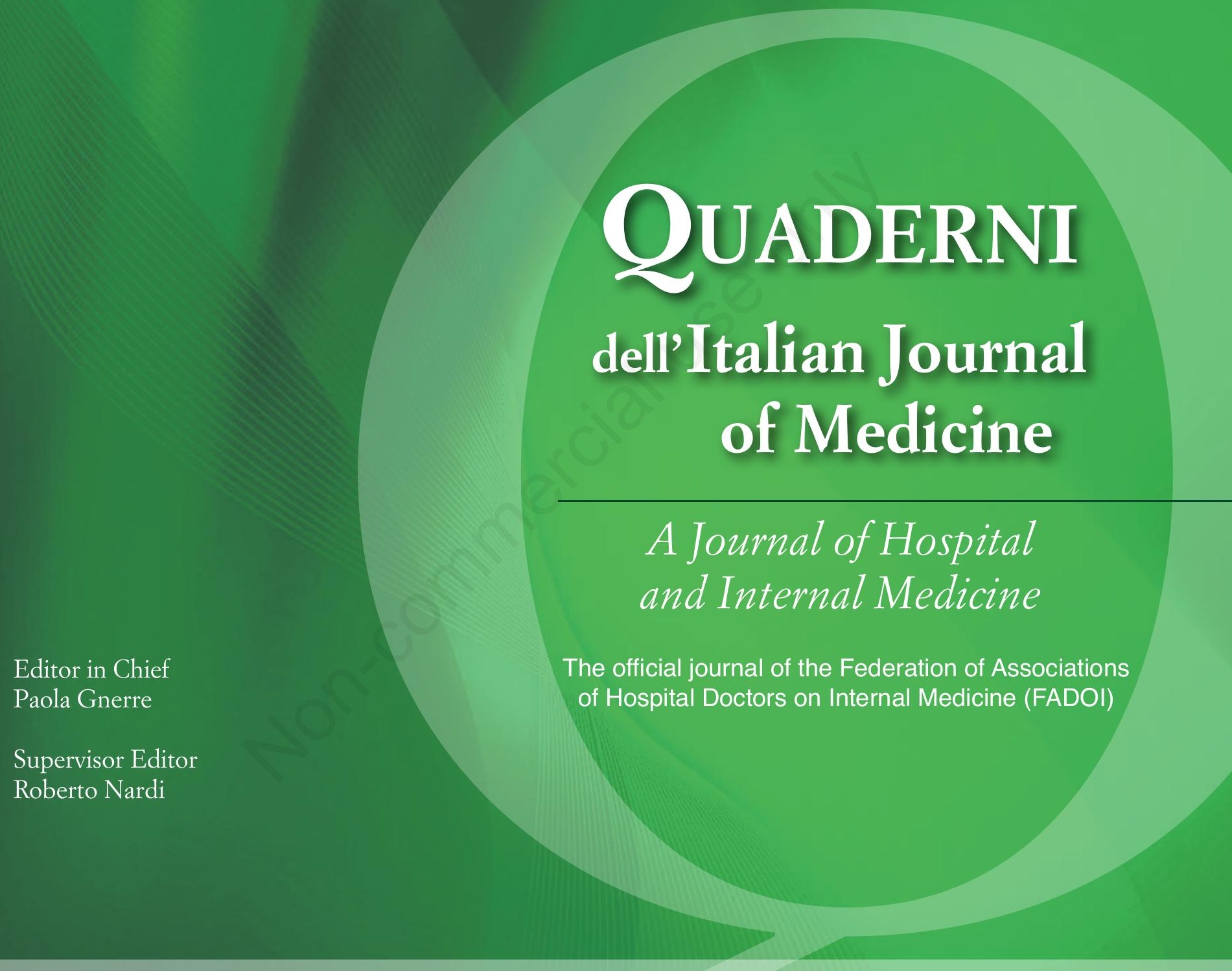

\title{
Le malattie respiratorie nell'ottica oll genere
}

Coordinatori: I. Ambrosino, E. Barbagelata

Guest Editors: P. Gnerre, C. Politi 
PRESIDENTE ELETTO

Dario Manfellotto, Roma, Italy

PAST PRESIDENT

Mauro Campanini, Novara, Italy

SEGRETARIO

Micaela La Regina, La Spezia, Italy

SEGRETARIO VICARIO

Andrea Montagnani, Grosseto, Italy

\section{STAFF DI SEGRETERIA}

\begin{tabular}{ll}
\hline Comunicazione & Claudia Tieri, Bari, Italy \\
Ricerca & Roberta Re, Novara, Italy \\
Formazione & Maurizia Gambacorta, Todi $(P G)$, Italy
\end{tabular}

TESORIERE

David Terracina, Roma, Italy

\section{STAFF DI TESORERIA}

Francesco D'Amore, Roma, Italy

PRESIDENTE FONDAZIONE FADOI

Mauro Campanini, Novara, Italy

COORDINATORE

Giuseppe Augello, Canicatti ( $A G)$, Italy

\section{DIPARTIMENTO PER LA RICERCA CLINICA FADOI}

Direttore Francesco Dentali, Varese, Italy

Supervisor per la Ricerca Giancarlo Agnelli, Perugia, Italy

DIPARTIMENTO PER LA FORMAZIONE

E AGGIORNAMENTO

Direttore Mauro Silingardi, Bologna, Italy

COORDINAMENTO FORMAZIONE

AREA CENTRO-NORD

Francesco Orlandini, La Spezia, Italy

COORDINAMENTO FORMAZIONE

AREA CENTRO-SUD

Generoso Uomo, Napoli, Italy

COORDINATORE COMMISSIONE GIOVANI

Flavio Tangianu, Oristano, Italy

MEMBRO FISM E RESPONSABILE

PER L'INNOVAZIONE IN MEDICINA INTERNA

Antonino Mazzone, Legnano (MI), Italy

ITALIAN JOURNAL OF MEDICINE

Editor in Chief Giorgio Vescovo, Padova, Italy
RESPONSABILE DEI

QUADERNI DELL'ITALIAN JOURNAL OF MEDICINE

Paola Gnerre, Savona, Italy

SUPERVISOR EDITOR DEI

QUADERNI DELL'ITALIAN JOURNAL OF MEDICINE

Roberto Nardi, Bologna, Italy

DELEGATO FADOI ITALIAN STROKE ORGANIZATION

E CONSULTA CARDIOVASCOLARE

Michele Stornello, Siracusa, Italy

\section{RAPPORTI CON EFIM}

Antonio Brucato, Bergamo, Italy

Gualberto Gussoni, Milano, Italy

Ombretta Para, Firenze, Italy

Giorgio Vescovo, Padova, Italy

RESPONSABILE SITO NAZIONALE

Salvatore Lenti, Arezzo, Italy

RESPONSABILE SISTEMA GESTIONE QUALITÀ

Franco Berti, Roma, Italy

RESPONSABILE CLINICAL COMPETENCE

Antonino Mazzone, Legnano (MI), Italy

RESPONSABILE AREA ECOGRAFIA

Francesco Cipollini, Ascoli Piceno, Italy

Marcello Romano, Catania, Italy

\section{RESPONSABILE MEDICINA DI GENERE}

Cecilia Politi, Isernia, Italy

\section{RESPONSABILE AREA NUTRIZIONE}

Roberto Risicato, Siracusa, Italy

Massimo Rondana, Pordenone, Italy

Luciano Tramontano, Praia a Mare (CS), Italy

RESPONSABILE AREA DI CLINICAL GOVERNANCE

Giovanni Iosa, Cesenatico ( $F C$ ), Italy

Stefano De Carli, Udine, Italy

\section{AREA SLOW MEDICINE}

Roberto Frediani, Chieri (TO), Italy

Luigi Lusiani, Castelfranco Veneto (TV), Italy

\section{AREA DOLORE}

Domenico Panuccio, Bologna, Italy

Giuseppe Civardi, Piacenza, Italy

\section{AREA CRITICA IN MEDICINA INTERNA}

Carlo Nozzoli, Firenze, Italy

\section{RESPONSABILE AGGIORNA FADOI}

Giuliano Pinna, Asti, Italy 


\section{Italian Journal of Medicine}

A Journal of Hospital and Internal Medicine

\section{PRESIDENTE FONDAZIONE}

Mauro Campanini, Novara, Italy

\section{COORDINATORE}

Giuseppe Augello, Canicattì ( $A G)$, Italy

\section{DIPARTIMENTO PER LA RICERCA CLINICA FADOI}

Direttore $\quad$ Francesco Dentali, Varese, Italy

Supervisor per la Ricerca Giancarlo Agnelli, Perugia, Italy

SEGRETERIA

Grazia Panigada, Pescia (PT), Italy

DELEGATO SIF

Francesco Rossi, Napoli, Italy

DELEGATO ANÍMO

Alberto Dal Molin, Novara, Italy

RESPONSABILE AREA MALATTIE CARDIOVASCOLARI

Paolo Verdecchia, Assisi (PG), Italy

\section{STAFF AREA MALATTIE CARDIOVASCOLARI}

Cecilia Becattini, Perugia, Italy

Pierpaolo Di Micco, Napoli, Italy

Fernando Gallucci, Napoli, Italy

Alessandro Squizzato, Varese, Italy

\section{RESPONSABILE AREA MALATTIE INFETTIVE}

Ercole Concia, Verona, Italy

\section{STAFF AREA MALATTIE INFETTIVE}

Anna Maria Azzini, Verona, Italy

Gianluca Giuri, Castelnovo ne'Monti (RE), Italy

Matteo Giorgi Pierfranceschi, Piacenza, Italy

Carlo Tascini, Pisa, Italy

\section{RESPONSABILE AREA MALATTIE RESPIRATORIE}

Leonardo Fabbri, Reggio Emilia, Italy

\section{STAFF AREA MALATTIE RESPIRATORIE}

Bianca Beghè, Reggio Emilia, Italy

Gaetano Cabibbo, Modica (RG), Italy

Francesco Corradi, Firenze, Italy

Francesco Ventrella, Cerignola $(F G)$, Italy

\section{RESPONSABILE AREA MALATTIE REUMATOLOGICHE}

Carlo Salvarani, Reggio Emilia, Italy

\section{STAFF AREA MALATTIE REUMATOLOGICHE}

Paola Faggioli, Legnano (MI), Italy

Laura Morbidoni, Senigallia (AN), Italy

Nicolò Pipitone, Reggio Emilia, Italy

Tito D'Errico, Napoli, Italy

\section{RESPONSABILE AREA MALATTIE METABOLICHE}

Roberto Vettor, Padova, Italy

\section{STAFF AREA MALATTIE METABOLICHE}

Tiziana Attardo, Agrigento, Italy

Giovanni Gulli, Savigliano (CN), Italy

Ada Maffettone, Napoli, Italy
Maurizio Nizzoli, Forli, Italy

RESPONSABILE AREA ORGANIZZATIVA

IN MEDICINA INTERNA

Antonio Greco, San Giovanni Rotondo ( $F G)$, Italy

\section{STAFF AREA ORGANIZZATIVA IN MEDICINA INTERNA}

Marco Candela, Jesi (AN), Italy

Giovanni Mathieu, Pinerolo (TO), Italy

Valentino Moretti, San Daniele del Friuli (UD), Italy

Filomena Pietrantonio, Brescia, Italy

Elisa Romano, La Spezia, Italy

DIRETTORE DIPARTIMENTO PER LA FORMAZIONE

E AGGIORNAMENTO

Mauro Silingardi, Bologna, Italy

COORDINAMENTO DI AREA FORMATIVA CENTRO-NORD

Francesco Orlandini, La Spezia, Italy

COORDINAMENTO DI AREA FORMATIVA CENTRO-SUD

Generoso Uomo, Napoli, Italy

STAFF DIPARTIMENTO PER LA FORMAZIONE

E AGGIORNAMENTO

Roberto Frediani, Chieri (TO), Italy

Marco Grandi, Sassuolo (MO), Italy

\section{SEGRETERIA DIPARTIMENTO PER LA FORMAZIONE} E AGGIORNAMENTO

Luigi Magnani, Voghera (PV), Italy

\section{BOARD SCIENTIFICO}

Clelia Canale, Reggio Calabria, Italy

Fabrizio Colombo, Milano, Italy

Giuseppe De Matthaeis, Città Sant'Angelo (PE), Italy

Massimo Giusti, Torino, Italy

Luca Masotti, Cecina (LI), Italy

Andrea Montagnani, Grosseto, Italy

Nicola Mumoli, Livorno, Italy

Maurizio Ongari, Porretta Terme (BO), Italy

Ruggero Pastorelli, Colleferro (RM), Italy

Fulvio Pomero, Savigliano (CN), Italy

Roberto Risicato, Siracusa, Italy

Antonio Sacchetta, Treviso, Italy

Giancarlo Tintori, Pisa, Italy

COMMISSIONE TECNICHE E METODICHE INNOVATIVE DI FORMAZIONE E VERIFICA

Responsabile dell'Innovazione in Medicina Interna

Antonino Mazzone, Legnano (MI), Italy

STAFF

Francesco Dentali, Varese, Italy

Andrea Montagnani, Grosseto, Italy

Filippo Pieralli, Firenze, Italy

\section{DIRETTORE SCIENTIFICO FONDAZIONE FADOI}

Gualberto Gussoni, Milano, Italy 


\title{
QUADERNI - Italian Journal of Medicine
}

\author{
LE MALATTIE RESPIRATORIE NELL'OTTICA DI GENERE \\ Coordinatori: I. Ambrosino, E. Barbagelata \\ Guest Editors: P. Gnerre, C. Politi
}

INTRODUZIONE

Introduzione

I. Ambrosino, E. Barbagelata

\section{RASSEGNE}

Differenze di genere nello sviluppo embrionale, nell'anatomia, nella fisiologia e nella patologia dell'apparato respiratorio ........ 3

E. Barbagelata, I. Ambrosino

Le principali malattie respiratorie in ottica di genere dall'epidemiologia alla diagnosi e alla terapia: asma

T. Ciarambino, O. Para, I. Ronga

Le principali malattie respiratorie in ottica di genere dall'epidemiologia alla diagnosi e alla terapia:

broncopneumopatia cronica ostruttiva.

S. Mangiacapra

Le principali malattie respiratorie in ottica di genere dall'epidemiologia alla diagnosi e alla terapia: polmoniti

T.M. Attardo

Le principali malattie respiratorie in ottica di genere dall'epidemiologia alla diagnosi e alla terapia: tromboembolia polmonare. M. Porru, P. Pitto

Le principali malattie respiratorie in ottica di genere dall'epidemiologia alla diagnosi e alla terapia: versamento pleurico

C. Zaninetti, C. Tana

Come una società scientifica può diffondere la cultura di genere? . . . 


\title{
Introduzione
}

\author{
Immacolata Ambrosino, ${ }^{1}$ Elena Barbagelata ${ }^{2}$ \\ ${ }^{1}$ Specialistica ambulatoriale, ASL Bari; ${ }^{2}$ Dipartimento di Medicina Interna, ASL 4 Chiavarese, Ospedale di Sestri Levante, \\ Sestri Levante (GE), Italia
}

Negli ultimi 20 anni la medicina di genere ha suscitato un interesse crescente, anche se non è sempre ben compresa nel suo reale significato e nella sua reale dimensione. Medicina di genere non vuol dire porre l'attenzione del mondo scientifico e clinico sulle patologie che incidono più frequentemente nell'uomo $o$ nella donna, oppure sulle patologie legate al sistema riproduttivo, o sulla salute delle donne. Medicina di genere significa comprendere in che modo le malattie di tutti gli organi e sistemi si manifestino nei due generi e, soprattutto, valutare le differenze di genere rispetto ai sintomi delle malattie, alla necessità di differenti percorsi diagnostici e interpretazioni dei risultati, alle differenze nella risposta ai farmaci o alla necessità di utilizzare farmaci diversi ed infine alle differenze rispetto alla prevenzione di tutte le malattie

La medicina di genere (MDG) ha l'obiettivo di comprendere i meccanismi attraverso i quali le differenze legate al sesso-genere agiscono sullo stato di salute, sull'insorgenza e sul decorso di molte malattie, nonché sugli outcomes delle terapie.

Gli uomini e le donne, infatti, pur essendo soggetti alle medesime patologie presentano sintomi, progressione di malattie e risposta ai trattamenti molto diversi tra loro. Da qui la necessità di porre l'attenzione allo studio delle differenze genere-specifiche delle malattie, inserendo questa nuova dimensione della medicina in tutte le aree mediche.

La MDG, dunque, è un approccio diverso e innovativo che si propone di assicurare la cura più appropriata a ciascun individuo, indipendentemente dal sesso, dall'età, dalla razza, dallo stato socio eco-

Corrispondente: Immacolata Ambrosino, Corso Benedetto Croce 165, 70125 Bari, Italia.

Fax: +39.080 .5520413$

E-mail: imma-ambrosino@libero.it

Articolo pubblicato secondo la Creative Commons Attribution NonCommercial 4.0 License (CC BY-NC 4.0).

CCopyright I. Ambrosino e E. Barbagelata, 2019

Licensee PAGEPress, Italy

QUADERNI - Italian Journal of Medicine 2019; 7(2):1-2 nomico e culturale, evitando diseguaglianze diagnostico-terapeutiche non motivate da chiare evidenze scientifiche.

La medicina di genere è oggi un argomento sul quale, sempre più spesso, si confrontano non solo le società scientifiche, ma più in generale tutte le istituzioni che hanno come obiettivo la promozione della salute in tutti i suoi vari aspetti, seguendo le indicazioni dell'Organizzazione Mondiale della Sanità (OMS). L'OMS ha infatti sottolineato l'importanza dell'attenzione al genere nei ruoli e nelle responsabilità delle donne e degli uomini, nell'accesso alle risorse, nella diversa posizione sociale e nelle regole sociali che sottendono e governano i loro comportamenti. Tra le politiche più recenti dell'OMS vi sono, inoltre, il monitoraggio delle diseguaglianze e la revisione delle politiche sanitarie, dei programmi e dei piani delle singole Nazioni, finalizzati ad assicurare gli outcomes di salute nel mondo.

Anche per il nostro Ministero della Salute il genere è un determinante essenziale di salute e come tale contribuisce a delineare nuove priorità, azioni, obiettivi e programmi; soltanto attraverso l'attuazione di una medicina genere-specifica, cioè di una medicina a misura di uomo e di donna, potranno essere perseguibili l'appropriatezza e la tutela della salute per entrambi i generi.

Le malattie respiratorie croniche (MRC) sono tra le principali cause di morbilità e mortalità e si prevede un trend in crescita per i prossimi anni. L'impatto delle MRC, oltre a causare morti premature, ha importanti effetti negativi sulla qualità della vita e sulla disabilità dei pazienti. In Italia le malattie respiratorie, dopo le malattie cardiovascolari e neoplastiche, rappresentano la terza causa di morte e si prevede che, anche a causa dell'invecchiamento della popolazione, la prevalenza di tali patologie sia destinata ad aumentare. ${ }^{1}$ Alcuni studi hanno evidenziato, sia in America che in Europa, una femminilizzazione di molte di queste patologie che prima costituivano un primato maschile. ${ }^{2}$

In Italia l'Health Examination Survey (OEC/HES) condotta nel periodo compreso tra il 2008 e il 2012 ha documentato che il 9,8\% delle persone tra 35-79 anni ha riferito di aver avuto una diagnosi di MRC e che la prevalenza di MRC aumenta nelle persone più anziane 
(14,5\% nella fascia di età 70-79 anni), in quelle con basso livello d'istruzione $(11,1 \%$ nelle persone con titolo di studio elementare o media inferiore), nei fumatori correnti $(10,6 \%)$ e negli ex-fumatori $(11,2 \%)$ e nelle persone in sovrappeso $(9,6 \%)$, in modo particolare negli obesi $(12,8 \%){ }^{3}$ Per valutare la funzionalità respiratoria, nel corso dell'indagine di popolazione OEC/HES 2008-2012, è stata eseguita una spirometria ed è emerso che la capacità vitale $(\mathrm{CV})$ ed il volume espiratorio massimo al primo secondo (VEMS) decrescono all'aumentare dell'età e risultano significativamente inferiori nelle persone con MRC, in particolar modo nelle classi di età più avanzate. ${ }^{3}$

Benché esistano efficaci misure preventive, le malattie respiratorie croniche sono sottovalutate, sottodiagnosticate, sottotrattate ed insufficientemente prevenute.

Le patologie respiratorie croniche sono particolarmente rilevanti non solo per il peso epidemiologico, ma anche per il risvolto economico e sociale e per la loro ricaduta su tutti i diversi livelli e strati del sistema sanitario e sociale. ${ }^{3}$

Le armi valide ed efficaci che abbiamo per cercare di ridurre la diffusione sempre più ampia di queste patologie risultano essere: i) la prevenzione primaria che deve essere volta alla sensibilizzazione della popolazione all'adozione di stili di vita sani; ii) lo sviluppo di indicatori per monitorare le MRC, per descrivere la prevalenza di queste patologie, i sintomi correlati, le diagnosi per gruppi di età, sesso, stato socio-economico e per area geografica; iii) il monitoraggio nel tempo di questi indicatori.

È quindi necessaria un'ampia sensibilizzazione di tutti gli operatori sanitari in questo arduo percorso in cui l'attenzione alle differenze di genere, nell'ambito delle MRC, rappresenta la chiave di volta per poter effettuare una corretta prevenzione, un precoce inquadramento diagnostico e un efficace trattamento terapeutico allo scopo di ridurre l'incidenza e la prevalenza di queste patologie, le iniquità sociali e le differenze socio-economiche e di limitare le disabilità che ne conseguono così da migliorare lo stato di salute e la qualità di vita di tutti i pazienti.

\section{Bibliografia}

1. Dati ISTAT 2010-2012.

2. Moretti AM, Gallone AS, Parisi D, et al. Gender differences and hospitalization for COPD: an analysis of the data from Puglia (Italy). Ital J Gender-Specific Med 2015; 1(2): 66-72.

3. Gruppo di lavoro GARD-Italy "Sorveglianza malattie Respiratorie"- http://www.salute.gov.it/imgs/C_17_ pubblicazioni_2386_allegato.pdf. 


\title{
Differenze di genere nello sviluppo embrionale, nell'anatomia, nella fisiologia e nella patologia dell'apparato respiratorio
}

\author{
Elena Barbagelata, ${ }^{1}$ Immacolata Ambrosino ${ }^{2}$ \\ ${ }^{1}$ Dipartimento di Medicina Interna, ASL 4 Chiavarese, Ospedale di Sestri Levante, Sestri Levante (GE); \\ ${ }^{2}$ Specialistica ambulatoriale, ASL Bari, Italia
}

Il polmone e le vie aeree presentano significative differenze nei due sessi in termini di sviluppo embrionale, caratteristiche anatomiche e funzionali. Il volume del polmone adulto femminile è più piccolo del $10 \%$ circa di quello maschile, a parità di età e altezza, a causa di una minore dimensione della gabbia toracica, maggiore inclinazione delle coste e minore lunghezza del diaframma. ${ }^{1}$ Il numero di alveoli per unità non differisce tra maschi e femmine ma, essendo il polmone maschile più grande del femminile, il numero totale degli alveoli e la superficie alveolare totale sono maggiori nel maschio rispetto alla femmina di pari età. ${ }^{2} \mathrm{Vi}$ è evidenza che lo sviluppo delle vie aeree nel sesso maschile avviene in modo disarmonico con un andamento relativamente lento di sviluppo in relazione alla crescita del volume polmonare (dysanaptic lung growth); nel sesso femminile si osserva invece una crescita delle vie aeree proporzionata ai volumi polmonari che determina flussi aerei più elevati a vari livelli di capacità polmonare totale, rispetto agli uomini. ${ }^{3}$ Pertanto nell'infanzia e fino all'adolescenza le donne presentano un vantaggio in termini di funzionalità respiratoria rispetto gli uomini (polmoni più piccoli e vie aeree di maggior calibro); al contrario nell'età adulta sono favoriti gli uomini che hanno polmoni di maggiori dimensioni e vie aeree di calibro maggiore.

Molteplici e non ancora del tutto noti sono i meccanismi fisiopatologici coinvolti nel determinare queste differenze anatomico-funzionali nei due sessi. Diversi modelli animali sono stati usati per studiare lo

Corrispondente: Elena Barbagelata, via A. Terzi, 43, Sestri Levante (GE), Italia.

E-mail: elenabarbagelata@yahoo.it

Articolo pubblicato secondo la Creative Commons Attribution NonCommercial 4.0 License (CC BY-NC 4.0).

CCopyright E. Barbagelata e I. Ambrosino, 2019

Licensee PAGEPress, Italy

QUADERNI - Italian Journal of Medicine 2019; 7(2):3-6 sviluppo del polmone, la fisiologia e la fisiopatologia e molti di questi studi hanno rivelato le diversità di genere in vari aspetti di questi processi. ${ }^{4}$ Studi sugli animali hanno evidenziato effetti significativi del sesso e degli ormoni sessuali sullo sviluppo polmonare normale già a partire dall'epoca embrionale, sulla fisiologia polmonare e nell'incidenza delle diverse malattie dell'apparato respiratorio. ${ }^{5}$

Gli ormoni steroidei sono sintetizzati principalmente nelle gonadi, nelle ghiandole surrenali e nell'unità feto-placentare. Il colesterolo, che è il precursore comune di tutti gli ormoni steroidei, viene prima convertito in pregnenolone e la via steroidogenica diverge poi verso la formazione di ormoni sessuali o dei glucocorticoidi o dei mineralcorticoidi. Nella via sintetica degli ormoni sessuali, il pregnenolone viene prima convertito in progesterone, che funge da intermedio per la sintesi di androgeni ed estrogeni. ${ }^{5,6}$ Gli estrogeni vengono sintetizzati dagli androgeni mediante la formazione di un anello aromatico A; questa reazione è catalizzata dall'enzima aromatasi. ${ }^{7}$ Gli ormoni steroidei sessuali agiscono attraverso i loro recettori: gli estrogeni attraverso il recettore estrogenico (ER) $\alpha$ o $\beta$; il progesterone attraverso il recettore del progesterone (PR) -A o PR-B ed infine gli androgeni attraverso il recettore degli androgeni (AR). ${ }^{8}$ Semplicisticamente parlando, i recettori degli ormoni steroidei legati al ligando si dimerizzano e si legano a specifici siti del DNA in grado di modulare la trascrizione. Negli ultimi anni, sembrerebbe da alcuni dati che il segnale del recettore dell'ormone steroideo sessuale non implichi sempre l'alterazione diretta della trascrizione genica, ma possa anche prevedere percorsi di attivazione cellulare rapida. ${ }^{6}$ È importante notare che tutti i recettori per gli ormoni steroidei sessuali hanno dimostrato di essere espressi nel tessuto polmonare. ${ }^{9,10}$

È ben noto in molte specie che la maturazione polmonare, misurata dalla produzione di tensioattivo surfactante, è ritardata nei feti maschi rispetto ai feti di sesso femminile. ${ }^{11,12}$

Diversi studi suggeriscono che la presenza di più alti livelli di androgeni nei feti maschi motivi questa differenza di concentrazione di surfactante tra i due 
sessi. Nel coniglio, la somministrazione di androgeni alle femmine in gravidanza ritarda la maturazione polmonare fetale, mentre la somministrazione dell'anti-androgeno flutamide abolisce la differenza di sesso nella maturazione polmonare, aumentando i livelli di tensioattivo maschile similmente a quelli delle femmine. ${ }^{11}$ I recettori per gli androgeni (Ars), che mediano gli effetti degli androgeni, sono presenti sia nei polmoni maschili che femminili, e nel polmone in via di sviluppo esiste un metabolismo attivo degli androgeni responsabile della sintesi e dell'inattivazione degli stessi. ${ }^{11}$

Nel topo, molti dei geni coinvolti nel metabolismo degli androgeni sono regolati specificamente nel giorno gestazionale 17,5 che coincide con la comparsa di cellule alveolari di tipo II mature, che sono responsabili della biosintesi dei tensioattivi. ${ }^{11,12}$ La sintesi e l'inattivazione del $5 \alpha$-diidrotestosterone, il più potente androgeno, sono relati all'attività della $5 \alpha$-reduttasi e della $3 \alpha$-idrossisteroide deidrogenasi (HSD), rispettivamente. Provost e Tremblay ${ }^{13}$ hanno recentemente dimostrato che l'espressione di $3 \alpha$-HSD aumenta notevolmente nel giorno 17,5 della gestazione quando si verifica la maturazione delle cellule alveolari di tipo II; questi risultati suggeriscono che l'RNA 3a-HSD potrebbe essere un indicatore affidabile di maturità polmonare nei feti. Dammann e colleghi ${ }^{14}$ hanno studiato alcuni dei meccanismi di segnalazione coinvolti nella regolazione degli androgeni sullo sviluppo del polmone del topo fetale ed hanno scoperto che il trattamento cronico con androgeni diminuisce l'attività del recettore del fattore di crescita epidermico (EGF) e aumenta l'attività del recettore del tumor growth factor (TGF), portando ad una inibizione dell'espressione genica di proteine del surfactante nelle cellule alveolari di tipo II.

Le differenze sessuali nella maturazione delle cellule alveolari di tipo II sono anche associate all'espressione differente di una varietà di altri geni rilevanti per lo sviluppo e la produzione di tensioattivo, compresi i geni che codificano per le apolipoproteine coinvolte nel trasporto dei lipidi.

Se il ruolo degli androgeni nella maturazione dei polmoni ha ricevuto molta attenzione, meno si conosce sul ruolo degli estrogeni in questo processo. I livelli plasmatici fetali di estrogeni sono in abbondanza nelle ultime fasi della gestazione in molte specie. ${ }^{15} \mathrm{La}$ somministrazione materna di estrogeni accelera la maturazione polmonare e stimola la produzione di tensioattivo nel coniglio e nel ratto fetali. Nei suinetti neonati, la deprivazione prenatale degli estrogeni riduce significativamente la formazione alveolare e la clearance dei liquidi. ${ }^{16}$

È stato a lungo riconosciuto che i bambini maschi sono a maggior rischio di sindrome da distress respiratorio rispetto ai bambini di sesso femminile; il liquido amniotico è stato ottenuto da 73 feti maschi e
76 femmine tra 28 e 40 sett. di gestazione. Per valutare la maturità polmonare fetale è stato determinato il rapporto lecitina-sfingomielina e le concentrazioni di fosfatidilcolina saturi e cortisolo in tutti questi fluidi. L'analisi della covarianza ha mostrato che i neonati di sesso femminile avevano indici più alti di maturità polmonare rispetto ai neonati maschi. La differenza di grado di maturità polmonare fetale era da 1,2 a 2,5 settimane, sulla base di queste misurazioni, con femmine in anticipo rispetto ai maschi. Gli autori hanno concluso che esiste una base biochimica per l'aumento del rischio di sindrome da distress respiratorio nei bambini maschi. ${ }^{5}$

Il canale del cloruro regolatore della conduttanza transmembrana della fibrosi cistica (CFTR) e il canale del sodio epiteliale $(\mathrm{ENaC})$ sono importanti nello sviluppo del polmone.

L'ENaC svolge un ruolo fondamentale nel riassorbimento attivo del fluido alveolare durante l'edema polmonare e alla nascita, un processo fondamentale per il passaggio dalla somministrazione placentare a quella polmonare di $\mathrm{O}_{2} \cdot{ }^{17} \mathrm{E}$ noto che il CFTR regola altri canali ionici, incluso $\mathrm{ENaC}$, e si ritiene che sia importante per la differenziazione dell'epitelio respiratorio durante lo sviluppo. Ratti femmina sessualmente maturi hanno livelli più alti di mRNA che codificano $\mathrm{ENaC}$ e CFTR rispetto ai maschi. La somministrazione combinata, ma non separata, di progesterone ed estradiolo aumenta i livelli di mRNA di subunità $\mathrm{ENaC} \mathrm{o}$ CFTR in ratti femmina sessualmente immaturi. Sweezey et al. hanno condotto uno studio sui ratti con il quale hanno concluso che l'aumentata espressione di $\mathrm{ENaC}$ nei polmoni femminili può conferire un vantaggio alle femmine di una migliore clearance del liquido polmonare fetale alla nascita o durante l'edema polmonare. ${ }^{17}$

All'inizio della maturità sessuale, ratti e topi femmine vergini presentano una superficie corporea di scambio gassoso (SA) e un alveolo più piccoli di massa specifica rispetto ai maschi di età corrispondente, sebbene non vi sia alcuna differenza nel consumo di ossigeno specifico di massa. Gli autori hanno ipotizzato che le differenze nelle SA e nelle dimensioni alveolari potrebbero essere state selezionate per evolvere in modo da aiutare le femmine a soddisfare le richieste metaboliche e di $\mathrm{O}_{2}$ della riproduzione. ${ }^{17}$ Successivamente è stato determinato che l'estrogeno è responsabile del dimorfismo sessuale nelle $\mathrm{SA}$ e nelle dimensioni alveolari. ${ }^{17}$ Ratti femmine trattati con estrogeni hanno più piccoli e più alveoli rispetto alle femmine che non assumono estrogeni. L'androgenizzazione dei ratti femmine appena nati non ha alcun effetto sulla SA o sulle dimensioni alveolari e, allo stesso modo, i topi con deficienza di AR hanno la stessa SA dei loro animali selvatici, ${ }^{17}$ escludendo quindi il coinvolgimento degli androgeni in questo 
particolare processo. Nei topi, l'estrogeno è richiesto anche per il mantenimento di alveoli già formati e induce la rigenerazione alveolare dopo la loro perdita in topi ovariectomizzati adulti. ${ }^{17}$

Gli estrogeni esercitano la maggior parte dei loro effetti attraverso ER $\alpha$ o ER $\beta$. Entrambi i recettori sono presenti nel polmone, con ER $\beta$ che è più abbondante di ER $\alpha .{ }^{18}$ Esaminando topi ER-deficienti (ERKO), è stato determinato che sia ER $\alpha$ che ER $\beta$ sono necessari per la formazione di un totale completamento di alveoli nei topi femmina, che ER $\alpha$ media il dimorfismo sessuale del numero alveolare specifico della massa corporea e SA e tale assenza di ER $\beta$ diminuisce il rinculo del tessuto elastico polmonare. Nei topi maschi, le ER hanno un effetto minore sulle dimensioni alveolari rispetto ai topi femmina. Patrone et al. ${ }^{18}$ hanno studiato i difetti alveolari in modo più dettagliato e hanno riscontrato carenze nel fattore di crescita A (PDGF-A) derivato dalle piastrine e nel fattore stimolante le colonie di granulociti/macrofagi (GM-CSF) nei polmoni dei topi $\beta E R K O$ adulti. Poiché sia il PDGF-A che il GM-CSF sono fattori critici nella produzione di alveoli e tensioattivi e sono controllati a livello trascrizionale da ER $\beta$, gli autori hanno concluso che i difetti alveolari nei topi $\beta E R K O$ potrebbero essere dovuti a modifiche nell'espressione di PDGF-A e GM-CSF. ${ }^{18}$

Le descritte differenze anatomico-strutturali correlate al genere hanno importanti ripercussioni sulla funzionalità polmonare e conseguentemente sulle malattie che colpiscono le vie repiratorie. L'analisi retrospettiva di un grosso studio prospettico di coorte condotto su pazienti affetti da BPCO severa sottoposti a intervento chirurgico di riduzione del volume polmonare documenta le disparità sesso-specifiche nella severità dei sintomi, nello stato di salute e nelle alterazioni patologiche valutati sia con metodiche radiologiche sia istologiche. ${ }^{19}$ Per una data età, percentuale predetta di FEV1, storia tabagica e quota di enfisema, le donne sperimentavano maggiore dispnea, punteggi più elevati di depressione, un'inferiore capacità di resistenza all'esercizio fisico e una peggiore qualità di vita rispetto alla controparte maschile. Agli accertamenti istologici le donne mostravano aree di enfisema, soprattutto severo, più piccole e minore interessamento periferico e vie aeree con pareti più spesse $\mathrm{e}$ quindi con lume sproporzionatamente ridotto.

Recentemente è stato scoperto che i topi maschi hanno un aumento del volume corrente e dei picchi di flusso inspiratorio rispetto ai topi femmina. ${ }^{20} \mathrm{La} \mathrm{ca}$ pacità polmonare totale e la pausa potenziata (Penh), una misura non invasiva della broncocostrizione, sono state segnalate come diverse nei topi maschi e femmine, con maschi che dimostrano maggiori risposte di Penh alla metacolina inalata e che possiedono polmoni più grandi rispetto alle femmine. ${ }^{20}$ Tuttavia, va notato che è stato espresso il dubbio sulla validità della mi- surazione di Penh. Viceversa, sebbene non sia stata riportata un'analisi morfometrica dettagliata, le vie aeree conduttrici di topi femmina sono state proposte per essere più grandi di quelle dei maschi. ${ }^{20}$

Le differenze sessuali impattano pure sulla funzione immunitaria, come è stato evidenziato sia negli uomini che negli animali. ${ }^{21}$ Infine i maschi presentano in genere risposte immunitarie più umorali e cellulomediate rispetto alle femmine..$^{22}$

\section{Bibliografia}

1. Bellemare F, Jeanneret A, Couture J. Sex Differences in Thoracic Dimensions and Configuration. American Journal Of Respiratory And Critical Care Medicine 2003;168:305-312.

2. Thurlbeck WM. Postnatal human lung growth. Thorax 1982;37:564-571.

3. Hoffstein V. Relationship between lung volume, maximal expiratory flow, forced expiratory volume in one second, and tracheal area in normal men and women. Am Rev Respir Dis 1986;134:956-961.

4. Carey MA, et al. The impact of sex and sex hormones on lung physiology and disease: lessons from animal studies. Am J Physiol Lung Cell Mol Physiol. 2007.

5. Torday JS, Nielsen HC, Montserrat De M. Fencl, et al. Sex Differences in Fetal Lung Maturation. American Review of Respiratory Disease 1981;123:205-208.

6. Carey MA, Card JW, Voltz JW, et al. The impact of sex and sex hormones on lung physiology and disease: lessons from animal studies. Am J Physiol Lung Cell Mol Physiol. 2007;293:272-8

7. Mendelsohn ME, Karas RH. Molecular and cellular basis of cardiovascular gender differences. Science 2005;10:1583-7.

8. Mangelsdorf DJ, Thummel C, Beato M, et al. The nuclear receptor superfamily: the second decade. Cell. 1995; 15:835-9.

9. Giannopoulos G, Smith SK. Androgen receptors in fetal rabbit lung and the effect of fetal sex on the levels of circulating hormones and pulmonary hormone receptors. J Steroid Biochem. 1982;17:461-5.

10. Moser EH, Daxenbichler G. Detection of a heat- and acid-stable 'progesterone'-binding protein in the rat lung. FEBS Lett. 1982;150:347-53.

11. Nielsen HC, Torday JS. Sex differences in fetal rabbit pulmonary surfactant production. Pediatr Res. 1981;15: 1245-7.

12. Torday JS, Dow KE. Synergistic effect of triiodothyronine and dexamethasone on male and female fetal rat lung surfactant synthesis. Dev Pharmacol Ther. 1984; 7:133-9.

13. Provost PR, Boucher E, Tremblay Y. Apolipoprotein AI, A-II, C-II, and $\mathrm{H}$ expression in the developing lung and sex difference in surfactant lipids. J Endocrinol. 2009;200:321-30.

14. Dammann CE, Nielsen HC. Regulation of the epidermal growth factor receptor in fetal rat lung fibroblasts during late gestation. Endocrinology 1998;139:1671-7.

15. Carnegie JA, Robertson HA. Conjugated and unconjugated estrogens in fetal and maternal fluids of the preg- 
nant ewe: a possible role for estrone sulfate during early pregnancy. Biol Reprod. 1978;19:202-11.

16. Trotter A, Ebsen M, Kiossis E, et al. Prenatal estrogen and progesterone deprivation impairs alveolar formation and fluid clearance in newborn piglets. Pediatr Res. 2006;60:60-4.

17. Sweezey N, Tchepichev S, Gagnon S, et al. Female gender hormones regulate mRNA levels and function of the rat lung epithelial Na channel. Am J Physiol. 1998; 274:379-86.

18. Patrone C, Tobias N, Cassel, et al. Regulation of Postnatal Lung Development and Homeostasis by Estrogen Receptor $\beta$. Mol Cell Biol. 2003;23:8542-8552.
19. Martinez FJ, Curtis JL, Sciurba F, et al. Sex differences in severe pulmonary emphysema Am J Respir Crit Care Med 2007;176:243-52.

20. Cabello N, Mishra V, Sinha U, et al. Sex differences in the expression of lung inflammatory mediators in response to ozone. Am J Physiol Lung Cell Mol Physiol. 2015;15.1150-63.

21. Schuurs AH, Verheul HA. Effects of gender and sex steroids on the immune response. J Steroid Biochem 1990;35:157-72.

22. Verthelyi D. Sex hormones as immunomodulators in health and disease. Int Immunopharmacol. 2001;1: 983-93. 


\title{
Le principali malattie respiratorie in ottica di genere dall'epidemiologia alla diagnosi e alla terapia: asma
}

\author{
Tiziana Ciarambino, ${ }^{1}$ Ombretta Para, ${ }^{2}$ Ilaria Ronga ${ }^{3}$ \\ ${ }^{1}$ UOC Medicina Interna, Ospedale Sarno, ASL Salerno; ${ }^{2}$ UOC Medicina Interna, AOU Careggi, Firenze; \\ ${ }^{3}$ Scuola di Specializzazione in Geriatria e Fibrosi Cistica dell'adulto, DAI Emergenze Cardiovascolari, Medicina Clinica e \\ dell'Invecchiamento, AOU Federico II, Napoli, Italia
}

\section{Introduzione}

L'asma bronchiale interessa circa 300 milioni di persone, con stime di prevalenza che vanno dall' 1 al $18 \%$ nei vari paesi, secondo i dati del rapporto GINA 2017. ${ }^{1}$ In Europa, circa 30 milioni di bambini ed adulti con età inferiore ai 45 anni sono asmatici. La prevalenza dell'asma nei vari paesi varia da meno del $3 \%$ della popolazione nei paesi dell'est europeo, a valori superiori al 9\% nel Regno Unito e nei paesi scandinavi. ${ }^{2}$ In Italia, secondo i dati raccolti dalla medicina generale, la prevalenza di asma nella popolazione italiana di età $>15$ anni è pari al $6,1 \%$, con una prevalenza leggermente maggiore nelle femmine $(6,6 \%)$ rispetto ai maschi $(5,5 \%)$. Tale prevalenza sembra diminuire con l'età. ${ }^{3}$ Questi dati trovano conferma nello studio GEIRD, che rileva una prevalenza del $6,6 \%$ nella popolazione italiana di 20-44 anni. ${ }^{4}$

L'Organizzazione Mondiale della Sanità stima che l'asma sia responsabile di circa 250.000 decessi l'anno e della perdita di 15 milioni di DALY (anni di vita aggiustati per la disabilità). ${ }^{5}$ Lo studio Global Burden of Diseases (GBD) ${ }^{6}$ ha valutato l'andamento nel tempo, dal 1990 al 2015, sia di asma che di BPCO. Tale studio ha riportato che nel 2015 sono decedute per asma circa 400.000 persone in tutto il mondo, con una riduzione della mortalità totale del $26,7 \%$ rispetto al 1990 ed una riduzione del 58,8\% della mortalità, standardizzata per età, rispetto al 1990. Inoltre, tale studio ha riportato

Corrispondente: Tiziana Ciarambino, UOC Medicina Interna, PO Sarno, ASL Salerno, Italia.

Tel.: +39.081.5666037

E-mail: tiziana.ciarambino@gmail.com

Articolo pubblicato secondo la Creative Commons Attribution NonCommercial 4.0 License (CC BY-NC 4.0).

(C) Copyright T. Ciarambino et al., 2019

Licensee PAGEPress, Italy

QUADERNI - Italian Journal of Medicine 2019; 7(2):7-11 che la più alta mortalità per asma, standardizzata per età, si era osservata nel genere maschile $(6,7$ per 100.000 abitanti) rispetto a quello femminile $(5,6$ per 100.000 abitanti). ${ }^{6}$

\section{Epidemiologia e genere}

Le differenze di prevalenza dell'asma tra i due sessi sono state documentate da molti studi internazionali e tendono ad avere un caratteristico andamento in base all'età della popolazione. La prevalenza dell'asma, infatti, è maggiore nei soggetti di sesso maschile in età infantile (rapporto maschi:femmine pari a circa 2:1), mentre nell'età puberale si verifica un'inversione del rapporto. Tali dati sono stati confermati anche dai dati raccolti nel 2012 dal Programma di ricerca sull'asma severo (Severe Asthma Research Program: SARP) promosso dal Centro per il controllo e Prevenzione delle patologie della National Health Interview Survey (NHIS), che ha dimostrato, come nella fascia di età compresa tra i 4 ed i 14 anni, la prevalenza di asma sia maggiore nei maschi rispetto alle femmine $(11,5$ vs $9,9 \%)$ ed inoltre tale studio ha dimostrato che tale rapporto si invertirebbe dopo la pubertà. ${ }^{7}$ Tali dati trovano ulteriore conferma anche dallo studio pubblicato dall'American Lung Association che ha dimostrato come la prevalenza di asma tra i soggetti con età inferiore ai 18 anni di età sia del $16 \%$ più alta nei maschi rispetto alle femmine, mentre tra gli adulti con età superiore a 18 anni, le femmine avevano una probabilità del $62 \%$ di sviluppare asma rispetto ai maschi. In tale studio, il tasso di prevalenza nelle femmine $(97,3 / 1000)$ era del $35 \%$ più alto rispetto a quello dei maschi $(71,9 / 1000) .{ }^{8}$ Risultati simili sono stati dimostrati anche nello studio European Comunity Health Respiratory Survey (ECRHS). ${ }^{9}$

Per quanto riguarda la situazione epidemiologica in Italia bisogna fare riferimento all'Italian Study of Asthma in Young Adults (ISAYA). ${ }^{10}$ Questo studio è stato condotto tra il 1998 e il 2000 su nove città italiane che hanno studiato un campione di 27.000 giovani adulti (20-44 anni). Lo scopo dello studio era 
quello di misurare la prevalenza e la variabilità geografica dell'asma e dei sintomi equivalenti asmatici, della rinite allergica, della tosse e del catarro cronici e di quantificarne i costi individuali e sociali dell'asma in Italia. Un successivo studio di follow-up sulla medesima popolazione è stato effettuato tra il 2000 ed il 2009 con lo scopo di stimare la frequenza di remissione. ${ }^{11}$ Dai dati dell'ECHRS, De Marco e colleghi hanno inoltre analizzato la prevalenza dell'asma in base all'età ed al sesso, mostrando che durante l'età infantile le femmine avevano un rischio molto più basso di ammalarsi di asma rispetto ai maschi (rischio relativo $[R R]=0,74$ nella fascia di età $0-5$ anni, e $\mathrm{RR}=0,56$ tra 5 e 10 anni). De Marco et al. hanno riportato inoltre che alla pubertà il rischio di sviluppare l'asma nella fascia di età tra 10 e 15 anni era sostanzialmente sovrapponibile tra i due sessi $(\mathrm{RR}=0,84$; intervallo di confidenza [IC] 95\%: 0,65-1,10) e che tale rischio aumentava per le femmine dopo la pubertà $(\mathrm{RR}=1,38$ rispetto a 5,91). In tale studio è stato inoltre dimostrato che la maggiore suscettibilità a soffrire di asma in età giovane adulta nelle femmine era in parte spiegata dal minore calibro delle loro vie aeree rispetto a quello dei maschi di pari età (odds ratio [OR] diminuiva dal 2,04 [95\%IC 1,32-3,15] al 1,47 [95\% IC: $0,98-2,44])$. Questa analisi ha confermato che l'incidenza dell'asma mostra un'inversione legata al sesso durante la pubertà, e suggerisce che il calibro delle vie aeree, in aggiunta ai fattori ormonali, possano giocare un ruolo importante nello spiegare il diverso pattern di incidenza tra maschi e femmine. ${ }^{12}$

Sono state formulate varie ipotesi per spiegare questa inversione di prevalenza all'età puberale, tutte incentrate sulle diverse modificazioni ormonali che hanno luogo durante lo sviluppo tra maschi e femmine.

\section{Possibili cause}

La differente crescita relativa di parenchima ed alveoli nei maschi rispetto alle femmine prende il nome di dysanapsis. A parità di peso ed altezza, alla nascita le bambine hanno polmoni più piccoli rispetto ai bambini. Inoltre, mentre nei soggetti di sesso femminile si verifica uno sviluppo armonico e sincrono di parenchima e vie aeree, ciò non si verifica nei soggetti maschi, nei quali la maturazione della quota parenchimale è più rapida di quella delle vie aeree. Pertanto, nelle prime fasi della vita, nonostante i polmoni più piccoli, le femmine hanno un calibro delle vie aeree maggiore rispetto ai maschi. Questo si traduce in un indice di funzionalità polmonare (VEMS/CVF) a favore delle femmine. Questa disparità di sviluppo del parenchima delle vie aeree si inverte nel passaggio alla pubertà $\mathrm{e}$ può essere in parte responsabile dell'aumento della severità dell'asma nelle femmine adulte..$^{13-15} \mathrm{Il}$ passaggio dall'età infantile a quella adulta è caratterizzato, inoltre, da una maggiore persistenza del wheezing nelle femmine, ${ }^{16,17}$ da un miglioramento dell'asma nei maschi associato ad un peggioramento della sintomatologia nelle femmine. ${ }^{18-21}$ Differenti studi hanno riportato che, dopo gli 11 anni di età, la concentrazione provocativa di metacolina necessaria a causare una riduzione del 20\% del FEV1 (PC20) aumentava negli adolescenti maschi suggerendo un miglioramento nella risposta delle vie aeree durante la pubertà nei maschi ma non nelle femmine, e tale effetto continuava a migliorare durante la completa maturazione sessuale..$^{22}$ L'età esatta dello switch di genere sembra possa essere compresa tra gli 11 ed i 18 anni. La prevalenza e la severità dell'asma sono frequentemente associate ai momenti chiave della vita riproduttiva del genere femminile, e questo suggerisce un ruolo di primaria importanza riservato agli ormoni sessuali femminili. Le femmine sembra che sperimentino un peggioramento dei sintomi dell'asma durante la fase pre-mestruale o mestruale del loro ciclo. È stato infatti coniato il termine di asma perimestruale per identificare questo fenomeno. ${ }^{23,24}$ Alcuni studi documentano che le variazioni nella funzione polmonare e nei sintomi asmatici non sembrano invece essere collegati alle variazioni ormonali. ${ }^{25}$ Altri studi supportano la presenza di un peggioramento dei sintomi durante la fase peri-mestruale, causando un aumentato utilizzo delle cure mediche..$^{25}$ Molti studi hanno inoltre collegato gli ormoni sessuali femminili con la severità dell'asma. Le donne con asma peri-mestruale sembra siano a più alto rischio di asma severo, richiedono più frequente uso di corticosteroidi inalatori ed hanno un rischio maggiore per visite urgenti, ospedalizzazione e ricovero in terapia intensiva ${ }^{26}$ Inoltre nelle femmine con asma, è stato osservato un anomalo livello di ormoni sessuali con conseguenti variazioni cicliche del FEV1 e del test di diffusione dei gas alveolari durante il ciclo mestruale, raggiungendo un picco alla fine della fase luteale e all'inizio della mestruazione. ${ }^{27,28}$ Queste caratteristiche correlate al ciclo mestruale sono state associate anche alle variazioni dello stato infiammatorio durante il periodo fertile tipico del genere femminile. Infatti, marcatori dell'infiammazione come ossido nitrico dell'esalato, eosinofili dell'espettorato, e livelli sierici del leucotriene $\mathrm{C} 4$ risulterebbero più elevati nelle femmine con sintomi asmatici severi, enfatizzando l'ipotesi che l'aumentata risposta infiammatoria possa essere responsabile del peggioramento dell'asma, che coincide con le fluttuazioni ormonali fisiologiche..$^{29,30}$ Le femmine asmatiche che ricevono contraccettivi orali, hanno inoltre variazioni della reattività delle vie aeree legate al ciclo, più attenuate in associazione alla riduzione del picco di estrogeni e progesterone durante la fase luteale. ${ }^{31}$ Inoltre è stato riportato che il rischio di asma, aumenta di due volte nelle femmine che hanno avuto un menarca precoce, ${ }^{32-34}$ mentre nelle donne plu- 
ripare, la prevalenza di asma aumenterebbe linearmente con il numero di parti. ${ }^{35}$ Questi risultati probabilmente sono associati al fatto che le bambine con menarca precoce e le gravide possano essere esposte a livelli più alti di ormoni sessuali, con conseguente rischio maggiore di sviluppare asma in età adulta. Per quanto riguarda infatti il ruolo della menopausa, secondo alcuni studi, durante la menopausa si verifica un peggioramento dei sintomi respiratori ed una riduzione del FEV1, ${ }^{36}$ secondo altri studi invece la menopausa pare possa avere un effetto protettivo. ${ }^{37}$ Tale ipotesi potrebbe essere correlata alla riduzione della severità dell'asma nelle femmine in menopausa tra i 50 ed i 65 anni rispetto ai maschi. Infatti con la menopausa si riducono i livelli di ormoni sessuali, con conseguente riduzione del rischio di asma nelle donne in post-menopausa rispetto alle donne in pre-menopausa. Altri studi dimostrano che tale effetto protettivo della menopausa sembra essere annullato dalla terapia ormonale sostitutiva. ${ }^{38,39}$

Un altro possibile fattore implicato nella genesi dell'asma sembra essere l'esposizione al fumo di sigaretta. Tale fattore di rischio è associato ad una maggiore severità dei sintomi asmatici, ${ }^{40}$ ad una peggiore risposta alla terapia corticosteroidea ${ }^{41}$ ed ad un maggiore declino della funzione polmonare. ${ }^{42}$

Anche l'obesità, è stato riportato che possa aumentare il rischio di asma nei bambini. In particolare è stato riportato che l'obesità centrale e la circonferenza vita possono essere associati con lo sviluppo di asma soprattutto nelle bambine. ${ }^{43}$

\section{Sintomatologia e genere}

Le differenze tra maschi e femmine per quanto riguarda l'asma non sono limitate solo alla prevalenza, ma anche alla diversa percezione dei sintomi tra maschi e femmine. Infatti differenti studi documentano una diversa percezione dei sintomi e dell'ostruzione bronchiale tra maschi e femmine. Nelle femmine infatti, i sintomi tendono ad essere più severi e di conseguenza determinano una qualità di vita peggiore, un peggiore controllo della loro malattia ed un più frequente utilizzo delle risorse sanitarie. A tale riguardo, uno studio longitudinale ha riportato che su 914 partecipanti di età tra i 3 ed i 55 anni, le femmine riportavano più sintomi e con maggior frequenza (numero di giorni la settimana) rispetto ai maschi $(\mathrm{p}<0,001)$ sia per le fasce di età comprese tra i 15 ed i 34 anni che per le fasce di età comprese tra i 35 ed i 55 anni. ${ }^{44} \mathrm{~L}$ 'asma nelle femmine, inoltre, si caratterizza per essere più severa e per un più frequente accesso alle risorse sanitarie, come riportato dall'European Network for Understanding Mechanisms of Severe Asthma (ENFUMOSA) ${ }^{45}$ Tale studio ha inoltre documentato un più alto rapporto femmine $v s$ maschi (4.4:1) per quanto riguarda l'asma severo, rispetto all'asma non severo. ${ }^{45}$ Inoltre in un' analisi di 1291 persone con riacutizzazioni di asma moderato-severo è stato riportato che il $62 \%$ dei pazienti erano femmine. ${ }^{46}$ Altro dato fondamentale è che anche la frequenza degli attacchi asmatici risulta più elevata nelle femmine rispetto ai maschi, come emerso dai dati dell'American Lung Association. In particolare, in tale studio è stato riportato che nel 2011, il 51,6\% delle femmine aveva avuto un attacco asmatico rispetto al $34,3 \%$ dei maschi. ${ }^{8}$ Dagli studi presenti in letteratura si evince che le femmine con asma presentano una qualità di vita peggiore, una più elevata percezione della dispnea, un più alto accesso alle cure, sono più frequentemente depresse, utilizzano più spesso gli inalatori di salvataggio e percepiscono una maggiore limitazione fisica. ${ }^{47-49}$

Sono necessari ulteriori studi per meglio identificare le differenze di mortalità per asma nelle femmine $v s$ maschi che tengano conto anche di fattori confondenti, quali invecchiamento, comorbilità ed esposizioni ambientali/lavorative.

\section{Messaggi chiave}

1. La prevalenza dell'asma nelle femmine ha un caratteristico andamento epidemiologico, risultando più frequente nei maschi in età pre-puberale, con una inversione di tendenza dopo la pubertà, epoca in cui l'asma diviene più frequente nelle femmine.

2. I fattori ormonali giocano un ruolo fondamentale sia per l'insorgenza che per le riacutizzazioni degli episodi asmatici, associandosi ai momenti chiave della vita riproduttiva del genere femminile.

3. L'asma nelle femmine viene riferito più severo ed associato ad un maggiore accesso alle cure mediche. I costi diretti dovuti alle ospedalizzazioni sono più alti nelle femmine rispetto ai maschi, anche a parità di severità dell'asma. Questo suggerisce che le femmine hanno una diversa percezione dei sintomi legati all'asma.

4. Le femmine con asma hanno una qualità di vita peggiore, una più intensa percezione della dispnea, sono più depresse, usano più di frequente inalatori rescue e sperimentano più limitazioni fisiche rispetto ai maschi (a parità di severità dell'asma $\mathrm{i}$ maschi hanno una funzione polmonare migliore).

\section{Bibliografia}

1. Global Initiative for Asthma, update 2017, www.ginasthma.org

2. Eurostat. Available from: http://ec.europa.eu/eurostat/statistics-explained/index.php/Respiratory_diseases_statistics. Last update: 10-11-2016.

3. Cazzola M, Puxeddu E, Bettoncelli, et al. (2011). The prevalence of asthma and COPD in Italy: a practicebased study. Respiratory Medicine, 105:386-391. 
4. De Marco R, Cappa V, Accordini S, et al. The GEIRD study group. (2012). Trends in the prevalence of asthma and allergic rhinitis in Italy between 1991 and 2010. European Respiratory Journal, 39:883-892.

5. Masoli M, Fabian D, Holt S, Beasley R, et al. The global burden of asthma: executive summary of the GINA Dissemination Committee report. Allergy. 2004 May;59(5): 469-78.

6. Global, regional, and national deaths, prevalence, disability-adjusted life years, and years lived with disability for chronic obstructive pulmonary disease and asthma, 19902015: a systematic analysis for the Global Burden of Disease Study 2015. Lancet Respir Med 2017;5:691-706.

7. Centers for Disease Control and Prevention. National Health Interview Survey (NHIS) Data 2012.

8. American Lung Association, Trends in Asthma Morbidity and Mortality [database on Internet], 2010.

9. Burney PG, Luczynska C, Chinn S, et al. The European Community Respiratory Health Survey. Eur Respir J. 1994 May;7(5):954-60.

10. Bugiani M, Carosso A, De Marco R. The European respiratory health survey and the Italian study on asthma in young adults: Goals, design and main results up to date. IT J Allergy Clin Immunol 2007;17:100-111.

11. Cazzoletti L, Corsico AG, Albicini F, et al. The course of asthma in young adults: a population-based nine-year follow-up on asthma remission and control. PLoS One. 2014 Jan 29;9(1):e86956. doi: 10.1371/journal.pone.0086956. eCollection 2014.

12. De Marco R, Locatelli F, Sunyer J, et al. Differences in incidence of reported asthma related to age in men and women. A retrospective analysis of the data of the European Respiratory Health Survey, Am. J. Respir. Crit. Care Med. 162 (2000) 68-74.

13. Becklake MR, Kauffmann F. Gender differences in airway behaviour over the human life span. Thorax. 1999; 54(12):1119-38.

14. Mead J. Dysanapsis in normal lungs assessed by the relationship between maximal flow, static recoil, and vital capacity. Am Rev Respir Dis. 1980;121(2):339-42.

15. Hibbert M, Lannigan A, Raven J, et al. Gender differences in lung growth. Pediatr Pulmonol. 1995;19(2):129-34.

16. Sears MR, Greene JM, Willan AR, et al. A longitudinal, population-based, cohort study of childhood asthma followed to adulthood. N Engl J Med. 2003;349(15): 1414-22.

17. Sekerel BE, Civelek E, Karabulut E, et al. Are risk factors of childhood asthma predicting disease persistence in early adulthood different in the developing world? Allergy. 2006 Jul;61(7):869-77.

18. Kjellman B, Gustafsson PM. Asthma from childhood to adulthood: asthma severity, allergies, sensitization, living conditions, gender influence and social consequences. Respir Med. 2000;94(5):454-65.

19. Kurukulaaratchy RJ, Karmaus W, Arshad SH. Gender differences in asthma development and remission during transition through puberty: the TRacking Adolescents' Individual Lives Survey (TRAILS) study. J Allergy Clin Immunol. 2010;126(3):498-504. e1-6.

20. Arshad S, Raza A, Lau L, et al. Pathophysiological characterization of asthma transitions across adolescence. Respir Res. 2014;15(1):153.

21. Andersson M, Hedman L, Bjerg A, et al. Remission and persistence of asthma followed from 7 to 19 years of age. Pediatrics. 2013;132(2):e435-42.

22. Tantisira KG, Colvin R, Tonascia J, et al. Airway responsiveness in mild to moderate childhood asthma: sex influences on the natural history. Am J Respir Crit Care Med. 2008 Aug 15;178(4):325-31.

23. Hanley SP. Asthma variation with menstruation, Br. J. Dis. Chest 75 (1981) 306-308.

24. Eliasson O, Scherzer HH, DeGraff AC. Morbidity in asthma in relation to the menstrual cycle, J. Allergy Clin. Immunol. 77 (1986) 87-94.

25. Gibbs CJ, Coutts II, Lock R, et al. Premenstrual exacerbation of asthma, Thorax 39 (1984) 833-836.

26. Rao CK, Moore CG, Bleecker E, et al. Characteristics of perimenstrual asthma and its relation to asthma severity and control: data from the Severe Asthma Research Program. 2013 Apr;143(4):984-992. doi: 10.1378/chest. 12-0973.

27. Rubio Ravelo L, Gago Rodríguez B, Almirall Collazo JJ, et al. Comparative study of progesterone, estradiol and cortisol concentrations in asthmatic and non-asthmatic women. Allergol Immunopathol (Madr). 1988 JulAug;16(4):263-6.

28. Farha S, Asosingh K, Laskowski D, et al. Effects of the menstrual cycle on lung function variables in women with asthma. Am J Respir Crit Care Med. 2009 Aug 15;180(4):304-10.

29. Skobeloff EM, Spivey WH, Silverman R, et al. The effect of the menstrual cycle on asthma presentations in the emergency department, Arch. Intern. Med. 156 (1996) 1837-1840.

30. Nakasato H, Ohrui T, Sekizawa K, et al. Prevention of severe premenstrual asthma attacks by leukotriene receptor antagonist, J. Allergy Clin. Immunol. 104 (3) (1999) 585-588.29.

31. Tan KS, McFarlane LC, Lipworth BJ. Modulation of airway reactivity and peak flow variability in asthmatics receiving the oral contraceptive pill. Am J Respir Crit Care Med. 1997;155(4):1273-7.

32. Al-Sahab B, Hamadeh MJ, Ardern CI, et al. Early menarche predicts incidence of asthma in early adulthood. Am J Epidemiol. 2011;173(1):64-70.

33. Salam MT, Wenten M, Gilliland FD. Endogenous and exogenous sex steroid hormones and asthma and wheeze in young women. J Allergy Clin Immunol. 2006; 117(5):1001-7. [PubMed: 16675325].

34. Fida NG, Williams MA, Enquobahrie DA. Association of Age at Menarche and Menstrual Characteristics with Adult Onset Asthma among Reproductive Age Women. Reprod Syst Sex Disord. 2012; 1(3).

35. Jenkins MA, Dharmage SC, Flander LB, et al. Parity and decreased use of oral contraceptives as predictors of asthma in young women. Clin Exp Allergy. 2006; 36(5):609-13.

36. Real FG, Svanes C, Omenaas ER, et al. Lung function, respiratory symptoms, and the menopausal transition. $\mathrm{J}$ Allergy Clin Immunol. 2008;121(1):72-80. e3.

37. Troisi RJ, Speizer FE, Willett WC, et al. Menopause, postmenopausal estrogen preparations, and the risk of adult-onset asthma. A prospective cohort study. Am J Respir Crit Care Med. 1995 Oct;152(4 Pt 1):1183-8.

38. Lange P, Parner J, Prescott E, et al. Exogenous female sex steroid hormones and risk of asthma and asthma- 
like symptoms: a cross sectional study of the general population. Thorax. 2001;56(8):613-6.

39. Jarvis D, Leynaert B. The association of asthma, atopy and lung function with hormone replacement therapy and surgical cessation of menstruation in a populationbased sample of English women. Allergy. 2008; 63(1):95-102.

40. Boulet LP, Lemiere C, Archambault B, et al. Smokyng and asthma: Clinical and radiologic features, lung function, and airway inflammetion. Chest. 2006;129(3): 661e668.

41. Livingston E, Chaudhur, McMahon AD, et al. Systemic sensitivity to corticosteroids in smokers with asthma. Eur Respkr J. 200;29(1):64e70.

42. Gibson PG, Simpson BL. The overlap syndrome of asthma and COPD: what are its features and important is it? Thorax. 2009;64:728e735.

43. Beneddtti FJ, Mocelin HT, Bosa VL, et al. Energy expenditure and estimated caloric intake in asthmatic adolescents with excess body weight. Nutrition 2010.

44. Osborne ML, Vollmer WM, Linton KL, et al. Charac- teristics of patients with a sthma within a large HMO: a comparison by age and gender, Am. J. Respir.Crit. Care Med. 157 (1998) 123-128.

45. European Network for Understanding Mechanisms of Severe Asthma. The ENFUMOSA cross-sectional European multicentre study of the clinical phenotype of chronic severe asthma. Eur Respir J. 2003;22(3):470-7.

46. Cydulka RK, Emerman CL, Rowe BH, et al. Differences between men andwomen in reporting of symptoms during an asthma exacerbation, Ann.Emerg. Med. 38 (2001) 123-128.

47. McCallister JW, Holbrook JT, Wei CY, et al. Sex differences in asthma symptom profiles and control in the American Lung Association Asthma Clinical Research Centers. Respir Med. 2013;107(10):1491-500.

48. Chhabra SK, Chhabra P. Gender differences in perception of dyspnea, assessment of control, and quality of life in asthma. J Asthma. 2011; 48(6):609-15.

49. de Miguel Díez J, Hernández Barrera V, Puente Maestu L, et al. Psychiatric comorbidity in asthma patients. J Asthma. 2011;48(3):253-8. 


\title{
Le principali malattie respiratorie in ottica di genere dall'epidemiologia alla diagnosi e alla terapia: broncopneumopatia cronica ostruttiva
}

\author{
Sara Mangiacapra \\ UOC di Medicina Interna, AORN "S.G. Moscati”, Avellino, Italia
}

\section{Introduzione}

La broncopneumopatia cronica ostruttiva (BPCO) è una comune malattia caratterizzata da persistenti sintomi respiratori e limitazione al flusso aereo, che è dovuta ad anomalie delle vie aeree e/o alveolari solitamente causate da una significativa esposizione a particelle nocive o gas. La cronica limitazione al flusso aereo caratteristica della BPCO è causata in parte dalle alterazioni a carico delle piccole vie aeree (es., bronchiolite ostruttiva) e in parte dalla distruzione parenchimale (enfisema); il contributo di ciascuna di queste due componenti varia da un individuo all'altro. L'infiammazione cronica causa dei cambiamenti strutturali; il restringimento delle piccole vie aeree e la distruzione del parenchima polmonare portano alla perdita degli attacchi alveolari alle piccole vie aeree e alla riduzione della forza di retrazione elastica polmonare. A loro volta, queste alterazioni riducono la capacità delle vie aeree di mantenersi pervie durante la fase espiratoria. Anche una perdita di elasticità a carico delle piccole vie aeree può contribuire alla limitazione al flusso aereo.

La BPCO rappresenta, ad oggi, la quarta causa di morte nel mondo. Si stima, inoltre, che nel 2020 diventerà la terza causa di morte nella popolazione mondiale. ${ }^{1}$ Tale patologia impatta significativamente sulla salute pubblica, in quanto rappresenta altresì un'importante causa di morbilità e disabilità cronica.

La prevalenza nella popolazione generale è stimata attualmente tra il 5 e il $15 \% .^{2}$

Corrispondente: Sara Mangiacapra, UOC di Medicina Interna, AORN "S.G. Moscati", Avellino, Italia.

E-mail: saramangiacapra1812@gmail.com

Articolo pubblicato secondo la Creative Commons Attribution NonCommercial 4.0 License (CC BY-NC 4.0).

(C) Copyright S. Mangiacapra, 2019

Licensee PAGEPress, Italy

QUADERNI - Italian Journal of Medicine 2019; 7(2):12-15
Tradizionalmente si è sempre ritenuto che la BPCO fosse una patologia di appannaggio maschile, a causa della maggiore diffusione, nel sesso maschile, dell'abitudine tabagica che rappresenta il principale fattore di rischio per lo sviluppo della patologia.

Tuttavia, negli ultimi decenni, abbiamo assistito ad un incremento sempre maggiore della sua prevalenza nel sesso femminile, tanto che si potrebbe parlare di una vera e propria femminilizzazione di tale patologia. Le cause di ciò sono molteplici. Innanzitutto bisogna considerare il ruolo del fumo di sigaretta che ha conosciuto, nelle ultime decadi, una crescente diffusione tra le donne. Inoltre è crescente nelle donne anche l'accesso a dei lavori e quindi a dei fattori di rischio occupazionali che precedentemente erano più tipici del sesso maschile (ad es. polveri e metalli pesanti tipici di alcune lavorazioni industriali). ${ }^{3}$ A questa maggiore esposizione ai fattori di rischio si associano fattori genetici e ormonali, in parte non ancora noti, che comportano una maggiore suscettibilità dell'apparato respiratorio femminile ad alcune noxae patogene, come ad esempio il fumo di sigaretta.

\section{Fisiopatologia}

Dal punto di vista fisiopatologico si rileva nelle donne una maggiore prevalenza di suscettibilità al fumo di sigaretta, a parità di esposizione, rispetto al sesso maschile. Inoltre sono state evidenziate, nei due sessi, anche delle differenze in rapporto al pattern istologico, in quanto nelle donne vi è prevalenza di malattia delle piccole vie aeree, con una minor presenza di enfisema, che prevale invece nel sesso maschile. ${ }^{4}$ Vi è evidenza in letteratura di un maggiore decremento del FEV1 nelle donne a parità di numero di pacchetti di sigarette consumati, nonché di una maggiore rischio di ospedalizzazione per BPCO nel sesso femminile. ${ }^{5}$ Una revisione sistematica di 11 studi ha, inoltre, dimostrato che le donne fumatrici hanno un più rapido decremento del FEV1/anno anche se fumano meno sigarette rispetto ai soggetti di sesso maschile. ${ }^{6}$

Sebbene i meccanismi alla base di questa maggiore 
suscettibilità non siano stati ancora completamente chiariti, le cause di ciò possono essere molteplici.

Innanzitutto bisogna considerare delle differenze anatomiche che sussistono tra maschi e femmine per quanto riguarda la conformazione dell'apparato respiratorio. Infatti gli uomini, a parità di peso e altezza, presentano polmoni di dimensioni maggiori e un maggior calibro delle vie aeree rispetto alle donne. Questo determina, a parità di esposizione, una maggiore concentrazione di sostanze inquinanti nelle vie aeree femminili rispetto a quelle maschili. ${ }^{7}$

Un altro meccanismo implicato nel danno da fumo nelle donne è l'influenza degli ormoni sessuali femminili. Tale meccanismo è stato studiato nel modello animale da Tam et al. ${ }^{8}$ In tale studio si metteva in evidenza come, nel modello murino, vi fosse, in risposta all'esposizione al fumo di sigaretta, un maggiore rimodellamento delle vie aeree nei topi di sesso femminile. Tale effetto era però annullato dall'ovariectomia, a dimostrazione del ruolo degli ormoni femminili in tale processo. Inoltre veniva rilevato come il tamoxifene, inibitore del recettore $\alpha$ degli estrogeni (ER $\alpha)$, avesse un effetto simile a quello dell'ovariectomia, indicando che gli estrogeni sono responsabili della maggiore suscettibilità al fumo osservata nei topi di sesso femminile. I meccanismi mediante i quali gli estrogeni comportano questo effetto sulle piccole vie aeree sono stati indagati nel medesimo studio, in cui si rilevava che nei topi di sesso femminile il fumo di sigaretta era associato con l'attivazione del transforming growth factor $\beta$ (TGF- $\beta$ ), con l'incremento dello stress ossidativo e la riduzione dell'espressione di fattori antiossidanti e della trascrizione del fattore Nrf2 (nuclear factor erythroid-derived 2-like 2) che regola la trascrizione di una serie di geni antiossidanti. Nel modello murino, la principale fonte di specie reattive dell'ossigeno sembra essere la NADPH-ossidasi-4 (NOX 4), a sua volta sovraregolata dal TGF- $\beta$, che sembra avere un ruolo nella fibrosi polmonare e nella proliferazione delle fibrocellule muscolari lisce a livello delle piccole vie aeree. Infine, lo stress ossidativo generato dalla NOX-4 nonché la riduzione degli antiossidanti promuovono l'attivazione del TGF- $\beta$, perpetrando un circolo vizioso di fibrosi e stress ossidativo.

Il fumo non è però l'unico fattore responsabile della BPCO. In effetti, il 15\% dei soggetti affetti da broncopneumopatia cronica ostruttiva non sono fumatori; di questi, circa $1^{\prime} 80 \%$ sono di sesso femminile. ${ }^{9}$ Tale dato suggerisce, quindi, una maggiore suscettibilità delle donne anche ad altri agenti causali diversi dal fumo di sigaretta. Come già sottolineato, importanti sono i fattori di rischio occupazionali derivanti dalle industrie e dall'agricoltura (polveri e metalli pesanti). In tali ambiti vi è stata, negli ultimi decenni, una diffusione sempre maggiore delle donne, con conseguente esposizione delle stesse a questi fattori di ri- schio tipicamente maschili. Le donne, inoltre, sono storicamente esposte, in misura maggiore rispetto agli uomini, a quello che viene definito inquinamento indoor, soprattutto nei paesi in via di sviluppo. La causa della maggiore suscettibilità a tali fattori nel sesso femminile non è stata ancora chiarita, ma probabilmente la risposta infiammatoria ha un ruolo fondamentale. In alcuni studi è stato indagato proprio il ruolo degli ormoni femminili nell'ambito dell'infiammazione. In particolare, sono emerse evidenze sul ruolo del progesterone che induce una risposta immunitaria di tipo Th2 anziché Th1, ${ }^{10}$ nonché cambiamenti ciclici nella produzione di interleuchina 8 (IL-8). ${ }^{11}$ Per quanto attiene il versante estrogenico, i cambiamenti ciclici nella concentrazione di estradiolo nelle donne sono stati associati a cambiamenti nella densità dei recettori adrenergici a livello polmonare e nella concentrazione di muco, acetilcolina e prostaglandine. ${ }^{12}$ L'estradiolo, inoltre, è in grado di aumentare l'espressione dei recettori per chemochine sui linfociti T. ${ }^{13}$

Infine è importante ricordare come l'asma rappresenti un fattore di rischio per lo sviluppo di BPCO nella popolazione generale. La prevalenza dell'asma è maggiore nelle donne, che inoltre sperimentano una peggiore qualità di vita e un maggior ricorso a cure mediche rispetto agli uomini. Probabilmente i fattori coinvolti sono vari, come ad esempio una maggiore iperreattività bronchiale, influenze ormonali, atopia, diversa percezione soggettiva del grado di ostruzione bronchiale.

\section{Quadro clinico}

Tra i due sessi sussistono rilevanti differenze anche per quanto riguarda l'espressione clinica della BPCO in termini di sintomatologia, diagnosi, comorbidità e accesso alle cure.

A parità di età e di grado di ostruzione delle vie aeree, nelle donne è presente maggiore dispnea. ${ }^{14} \mathrm{Sin}$ tomi quali tosse e catarro, invece, sono più presenti nel sesso maschile. ${ }^{15} \mathrm{Ci}$ sono vari fattori che possono spiegare la maggior presenza di dispnea nelle donne. Innanzitutto, ci sono fattori anatomici che nel sesso femminile comportano una ridotta capacità ventilatoria, una maggiore limitazione al flusso espiratorio, una lieve riduzione nel volume di fine espirazione durante l'esercizio fisico e un aumento del lavoro respiratorio. Inoltre, a parità di livello di ostruzione delle vie aeree, le donne presentano una maggiore iperreattività bronchiale. ${ }^{16}$

Per quanto riguarda le comorbidità, sostanzialmente risultano più frequenti nel sesso maschile le comorbidità cardiologiche, in primis aritmie e cardiopatia ischemica. È da rilevare, a tal proposito, che però le donne meno frequentemente si rivolgono allo specialista cardiologo, ${ }^{15}$ per cui in questo dato ci potrebbe essere un bias consistente in una underdiagno- 
sis di patologie cardiologiche asintomatiche o paucisintomatiche nelle donne. Più frequente nel sesso maschile risulta anche la sindrome delle apnee ostruttive del sonno. Comorbidità che invece si ritrovano più di frequente nel sesso femminile sono costituite da: osteoporosi, ansia e depressione. Controverso invece il dato sull'obesità: in alcune casistiche risulta più frequente nel sesso maschile, ${ }^{16}$ in altre nel sesso femminile ove si rileva un BMI mediamente più alto. ${ }^{15}$

Interessante anche analizzare l'aspetto dell'accesso alle cure e della percezione delle stesse nei due sessi. Nello studio di Martinez et al. ${ }^{15}$ si metteva in evidenza come le donne, in generale, risultano meno soddisfatte delle cure e del rapporto medico-paziente. In particolare le donne ritenevano di aver avuto un ritardo nella diagnosi e sperimentavano una difficoltà a raggiungere il curante. Inoltre, lamentavano una scarsa empatia nel rapporto medico-paziente e ritenevano insufficiente il tempo loro dedicato dal curante in maniera maggiore rispetto agli uomini. Parallelamente le donne, più frequentemente degli uomini, si ritenevano meno informate sulla loro condizione di salute e cercavano fonti alternative di informazioni rispetto al loro medico (internet, altri pazienti, ecc.).

\section{Terapia}

Obiettivi del trattamento della BPCO sono la riduzione dei sintomi, della frequenza e della gravità delle riacutizzazioni, il miglioramento dello stato di salute e della tolleranza allo sforzo. A tale scopo vengono utilizzati trattamenti non farmacologici, ovvero la cessazione dell'abitudine tabagica e la riabilitazione respiratoria, nonché trattamenti farmacologici. Le principali classi di farmaci utilizzati nel trattamento della BPCO sono le seguenti: i) broncodilatatori: beta 2 agonisti, antimuscarinici, metilxantine; ii) farmaci che agiscono sull'infiammazione: corticosteroidi inalatori, corticosteroidi per via orale, inibitori della fosfodiesterasi-4 (PDE-4).

Anche nel trattamento sono state rilevate alcune differenze di genere.

\section{Cessazione del fumo}

La cessazione del fumo è l'unico intervento che si è dimostrato in grado di rallentare il deterioramento della funzionalità polmonare. Le donne sono più suscettibili al fumo di sigaretta e trarrebbero un maggiore beneficio dalla cessazione del fumo stesso. Come dimostrato nel Lung Health study, ${ }^{17}$ le donne che smettevano di fumare sperimentavano un miglioramento nel FEV1 2,5 volte maggiore rispetto agli uomini.

\section{Terapia farmacologica}

Le attuali strategie di trattamento farmacologico della BPCO (utilizzate sia nelle donne che negli uomini) sono applicate sulla base di trials clinici che hanno reclutato in maggioranza soggetti di sesso maschile. In effetti, nella maggioranza dei trials clinici terapeutici, le donne rappresentano soltanto il 20-25\% dei soggetti arruolati. In realtà ci sono una serie di fattori che fanno ipotizzare delle differenze di genere nella risposta ai trattamenti farmacologici nella broncopneumopatia cronica ostruttiva. Come abbiamo già ricordato, nelle donne vi è meno enfisema e una maggior presenza di malattia delle piccole vie aeree. Inoltre nel sesso femminile è stata osservata una maggiore broncoreattività a stimoli aspecifici (come la metacolina) rispetto al sesso maschile, a parità di ostruzione delle vie aeree. Tra i due sessi vi sono altresì delle differenze per quanto riguarda il metabolismo dei farmaci e degli agenti chimici (compresi quelli correlati al fumo di sigaretta), differenze legate sia alla diversa espressione di enzimi della famiglia dei citocromi (probabilmente anche in risposta a fattori ormonali) sia alla diversa espressione di proteine che rappresentano i target dei farmaci stessi. In letteratura iniziano ad emergere evidenze circa un possibile diverso effetto della terapia inalatoria nei due sessi. In particolare in uno studio del 2017, ${ }^{18}$ è stata indagata la differente risposta nei due sessi a uno dei primi farmaci inalatori utilizzati nel trattamento della BPCO: 1'ipratropio bromuro. In questo studio si metteva in evidenza come nelle donne vi fosse una maggiore risposta broncodilatatoria all'ipratropio, evidenziata con un maggiore incremento del FEV1 nel sesso femminile. L'entità di tale miglioramento risultava correlata inversamente al BMI nelle donne, correlazione, questa, che non si osservava nel sesso maschile. Nello stesso studio veniva messo in evidenza come nel sesso femminile vi fosse una maggiore espressione del recettore muscarinico M3 rispetto a M2, che potrebbe costituire la base biochimica delle differenze osservate. L'ipratropio è un inibitore non selettivo del recettore muscarinico, che agisce sia sui recettori M2 che sui recettori M3. Il recettore M3 è il recettore muscarinico che induce broncocostrizione mediante la contrazione della muscolatura liscia bronchiale. Il recettore M2, invece, è un recettore espresso sia a livello pre- che post- sinaptico. Il recettore presinaptico M2 è un autorecettore, che previene il rilascio di acetilcolina. Il recettore postsinaptico M2 attenua l'attività dell'adenilato ciclasi inducendo il rilassamento delle fibrocellule muscolari lisce. Pertanto i recettori M2, in sostanza, favoriscono la broncodilatazione. È evidente come un elevato rapporto M3/M2 nel sesso femminile, come osservato in questo studio, comporti una maggior risposta broncodilatatoria all'ipratropio, facendo preva- 
lere il blocco $\mathrm{M} 3$, rispetto a soggetti in cui il rapporto $\mathrm{M} 3 / \mathrm{M} 2$ sia più basso.

A questo punto sarebbe auspicabile effettuare ulteriori studi che indaghino anche l'effetto sui due sessi dei farmaci M3 selettivi e delle combinazioni di broncodilatatori per mettere in evidenza eventuali differenze di genere.

\section{Conclusioni}

In conclusione, la valutazione della BPCO nell'ottica di genere fa emergere evidenti differenze tra i due sessi, per quanto riguarda la fisiopatologia, la clinica, nonché l'approccio terapeutico. Tali differenze sono rilevanti dal punto di vista pratico, in quanto la loro valutazione potrebbe suggerire un approccio sessospecifico a tale patologia, sia nell'elaborazione di algoritmi diagnostici che di strategie terapeutiche diversificate $\mathrm{e}$, in quanto tali, più efficaci.

\section{Bibliografia}

1. GOLD 2017 guidelines available on http:/goldcopd.it/wpcontent/uploads/materiali/2017/GOLD_workshop_report 2017.pdf

2. Viegi G, Pistelli F, Sherill DL, et al. "Definition, epidemiology and natural history of COPD". Eur Respir J. 2007;30(5):993-1013.

3. Aryal S, Diaz-Guzman E, Mannino D. "Influence of sex on chronic obstructive pulmonary disease risk and treatment outcome". International Journal of COPD 2014:9 1145-1154.

4. Martinez FJ, Curtis JL, Sciurba F, et al. "National Emphysema Treatment trial Research Group. Sex differences in severe Pulmonary emphysema" Am J Respir Crit Care Med 2007;176:243-252.

5. Martinez CH, Raparla S, Craig A. Plauschinat et al. "Gender Differences in Symptoms and care delivery for Chronic Obstructive Pulmonary Disease". Journal of women's health Vol. 21, no. 12:2012;1267-1274.

6. Wen Qi Gan, SF Paul Man, Dirkje S, et al. "Female smokers beyond the perimenopausal period are at increased risk of chronic obstructive pulmonary disease: a systematic review and meta-analysis" Respiratory
Research 2006, 7:52 doi:10.1186/1465-9921-7-52.

7. Carey MA, Card JW, Voltz JW, et al. "It's all about sex: male-female differences in lung development and disease " Trends Endocrinol Metab. 2007 October; 18(8): 308-313.

8. Tam A, Churg A, Wright JL, et al. "Sex differences in Airway remodeling in a mouse model of Chornic Obstructive Pulmonary Disease" Am J Respir Crit Care Med. 2016 Apr 15;193(8):825-34.

9. Celli BR, Halbert RJ, Nordyke RJ, et al. "COPD in never smokers: a significant problem? Airway obstruction in never smokers: results from the Third National Health and Nutrition Examination Survey" Am J Med. 2005;118:1364-1372.

10. Piccinni MP, Giudizi MG, Biagiotti R, et al. Progesterone favors the development of human $\mathrm{T}$ helper cells producing Th2-type cytokines and promotes both IL-4 production and membrane CD30 expression in established Th1 cell clones. J Immunol 1995;155:128-133.

11. Kelly RW, Illingworth P, Baldie G, et al. Progesterone control of interleukin- 8 production in endometrium and choriodecidual cells underlies the role of the neutrophil in menstruation and parturition" Hum Reprod 1994;9: 253-258.

12. Becklake MR, Kauffmann F. Gender differences in airway behavior over the human life span. Thorax 1999;54: 1119-1138.

13. Mo R, Chen J, Grolleau-Julius A, et al. Estrogen regulates CCR gene expression and function in T lymphocytes. J Immunol 2005; 174:6023-6029.

14. Roche N, Deslée G, Caillaud D, et al. "Impact of gender on COPD expression in a real life cohort". Respiratory Research 2014;15:20.

15. Martinez CH, Raparla S, Plauschinat CA, et al. "Gender Differences in Symptoms and Care Delivery for Chronic Obstructive Pulmonary Disease" Journal of Women's Health Vol. 21, no. 12, 2012, 1267-1274.

16. Camp PG, Coxson HO, Levy RD, et al. "Sex differences in emphysema and airway disease in smokers" Chest 2009; 136:1480-1488.

17. Scanlon PD, Connet JE, Waller LA, et al. "Smoking cessation and lung function in mild-to-moderate chronic obstructive pulmonary disease. The Lung Health Study" Am J respir Crit Care Med. 2000;161:381-390.

18. Xuan Li, Obeidat M, Zhou G, et al. "Responsiveness to Ipratropium bromide in Male and female Patients with mild to moderate Chronic Obstructive Pulmonary Disease", EbioMedicine 19 (2017) 139-145. 


\title{
Le principali malattie respiratorie in ottica di genere dall'epidemiologia alla diagnosi e alla terapia: polmoniti
}

\author{
Tiziana Marcella Attardo \\ UO di Medicina Interna, Ospedale Barone Lombardo di Canicattì, Asp 1, Agrigento, Italia
}

\section{Polmoniti di genere: le evidenze della letteratura}

Matthew E. Falagas et al. ${ }^{1}$ hanno esaminato le evidenze disponibili nella letteratura riguardo alle differenze di genere nell'incidenza e nella gravità delle infezioni delle vie respiratorie (RTI). Dall'extraction - data degli 84 studi pertinenti sono state ottenute informazioni sulle differenze di genere nell'incidenza e nella gravità delle RTI ed è emerso che le femmine sono più comunemente colpite da infezioni del tratto respiratorio superiore, in particolare sinusite, tonsillite e otite esterna. D'altra parte, i maschi sono più comunemente colpiti da otite media ed infezioni del tratto respiratorio più basso. È anche palese dalle evidenze che il decorso della maggior parte delle RTI è più grave nei maschi che nelle femmine, portando ad una maggiore mortalità nei maschi, specialmente nel caso delle polmoniti acquisite in comunità.

In conclusione, i dati disponibili suggeriscono che i maschi sono più a rischio delle femmine per la maggior parte dei tipi di RTI ed in tutte le fasce di età (adulti e bambini). Complessivamente, dunque, sembra che i maschi sviluppino più frequentemente RTI rispetto alle femmine, ad eccezione di sinusite, otite esterna e probabilmente tonsillite.

I dati clinici, tuttavia, appaiono contrastanti. Crabtree e colleghi hanno riscontrato che le donne che sviluppano polmonite nosocomiale hanno outcomes peggiori rispetto agli uomini, dopo aggiustamento per

Corrispondente: Tiziana Marcella Attardo, UO di Medicina Interna, Ospedale Barone Lombardo di Canicattì, Asp 1, Agrigento, Italia.

Tel.: +39.0922733212.

E-mail: claudia.fantucchio@alice.it

Articolo pubblicato secondo la Creative Commons Attribution NonCommercial 4.0 License (CC BY-NC 4.0).

(C) Copyright T.M. Attardo, 2019

Licensee PAGEPress, Italy

QUADERNI - Italian Journal of Medicine 2019; 7(2):16-20 età e gravità della malattia. ${ }^{2}$ Altri non hanno riscontrato alcuna differenza di genere sulla mortalità ${ }^{3}$ ed altri hanno evidenziato outcomes migliori nelle donne. ${ }^{4}$

Le donne sono più suscettibili alle pneumopatie su base infiammatoria secondarie all'inquinamento atmosferico e mostrano outcomes peggiori rispetto agli uomini. Tuttavia, i meccanismi alla base di queste differenze rimangono sconosciuti.

Certamente, le differenze anatomiche, di stile di vita, comportamentali e socio-economiche tra maschi e femmine possono spiegare, almeno in parte, $i$ risultati osservati. Inoltre il ruolo degli ormoni sessuali nella regolazione del sistema immunitario può anche contribuire alle differenze di genere riportate nell'incidenza e nella gravità dei vari tipi di RTI, specialmente negli adolescenti e negli adulti.

Noe Cabello et al. ${ }^{5}$ hanno ipotizzato che le differenze di genere nell'espressione dei mediatori dell'infiammazione polmonare influenzino le risposte immunitarie specifiche del sesso alle sostanze tossiche ambientali. In particolare gli autori si sono concentrati sugli effetti dell'ozono, un importante inquinante atmosferico, a livello del suolo nell'espressione e nella regolazione dei geni dell'immunità polmonare. L'esperimento, eseguito su topi adulti maschi e femmine esposti, per 3 ore, a $2 \mathrm{ppm}$ di ozono o aria filtrata (gruppo controllo), consisteva nel confrontare i livelli di mRNA di 84 geni infiammatori nei polmoni raccolti 4 ore dopo l'esposizione utilizzando PCR array. Inoltre, sono stati valutati i cambiamenti nell' istologia polmonare e nella conta delle cellule dei fluidi da lavaggio broncoalveolare e il contenuto proteico a 24 e 72 ore dopo l'esposizione. I risultati dello studio hanno rivelato differenze di genere nell'infiammazione polmonare innescata dall'esposizione all'ozono, nell'espressione di geni coinvolti nella fase acuta e nelle risposte infiammatorie. Differenze tra i due sessi sono state riscontrate nell'espressione di chemochine che attraggono i neutrofili (Ccl20, $\mathrm{Cxcl} 5$ e Cxcl2), della citochina interleuchina- 6 proinfiammatoria e degli enzimi correlati allo stress ossidativo (Ptgs2, Nos2). Inoltre, la fosforilazione di STAT3, nota per mediare le risposte immunitarie correlate all'IL-6, era significativamente più alta nei topi esposti all'ozono. 
Nell'insieme queste osservazioni suggeriscono che una regolazione differenziale della risposta immunitaria polmonare potrebbe essere implicata nell'aumentata suscettibilità osservata nelle donne rispetto agli uomini, agli effetti avversi derivanti dall'ozono. ${ }^{5}$

La polmonite acquisita in comunità (CAP) è una causa frequente di ricovero ospedaliero e morte tra $\mathrm{i}$ pazienti anziani, ma ci sono poche informazioni sull'incidenza specifica per età e sesso, sui modelli di cura (ammissione in unità di terapia intensiva e ventilazione meccanica), sull'uso delle risorse (durata del soggiorno e costi ospedalieri) e sui risultati (mortalità). Per ciò che riguarda la CAP sono stati condotti diversi studi riguardanti i potenziali fattori di rischio per il suo sviluppo. La maggior parte di essi ha arruolato pazienti ospedalizzati. Nella maggior parte di questi studi (e in particolare in quelli di maggiori dimensioni), gli uomini erano statisticamente più frequentemente arruolati e in alcuni di essi il sesso maschile rappresentava un fattore di rischio per CAP o di ospedalizzazione per CAP.

Kaplan et al. ${ }^{6}$ hanno condotto uno studio di coorte osservazionale tra la popolazione di Medicare, di età pari o superiore a 65 anni, ricoverati nel 1997 in ospedali non federali degli Stati Uniti che soddisfacevano i criteri basati su ICD-9-CM per la CAP. L'obiettivo dello studio era di fornire una valutazione contemporanea dell'incidenza, dei modelli di cura e degli esiti della CAP nella popolazione anziana degli Stati Uniti e di determinare le differenze per età e sesso. Sono stati identificati 623.718 ricoveri ospedalieri per CAP $(18,3$ per 1000 abitanti di età $\geq 65$ anni), di cui $26.476(4,3 \%)$ provenivano da case di cura e di cui $66.045(10,6 \%)$ sono deceduti. L'incidenza risultava aumentata di cinque volte e la mortalità raddoppiata con l'aumentare dell'età da 65-69 anni a oltre 90 anni. Gli uomini avevano una mortalità più alta, sia senza aggiustamento (odds ratio [OR]: 1,21 [IC 95\%: 1,19-1,23]) che dopo aggiustamento per età, provenienza del paziente, comorbidità sottostante ed eziologia microbiologica (OR: 1,15 [IC 95\%: 1,13-1,17]). Gli Autori concludevano che le differenze di genere riscontrate certamente richiedevano ulteriori indagini.

L'importanza prognostica del genere nei pazienti ospedalizzati è stata scarsamente studiata. Lo studio di Gordon ${ }^{7}$ ha confrontato i tassi di mortalità ospedaliera tra uomini e donne dopo aggiustamento per gravità della malattia. Si trattava di 89.793 pazienti eleggibili con 6 comuni diagnosi non chirurgiche dimessi da 30 ospedali nel nord-est dell'Ohio nel periodo 1991-1993. La severità di ammissione della malattia (cioè il rischio di morte previsto) è stata calcolata utilizzando modelli multivariabili basati su dati estratti dalle cartelle cliniche dei pazienti (aree della curva ROC, 0,83-0,90). In ospedale i tassi di mortalità sono stati, quindi, adeguati ai rischi di morte predetti e ad altre covariate utilizzando l'analisi di regressione logistica. Le probabilità di morte corrette erano più elevate $(\mathrm{P}<0,05)$ negli uomini rispetto alle donne, per 4 diagnosi: ictus [OR, 1,60], broncopatia cronica ostruttiva [OR 1,38], emorragia gastrointestinale [OR $1,32]$ e polmonite [OR, 1,18]) e simili per due diagnosi: insufficienza cardiaca congestizia [OR, 1,12] ed infarto miocardico acuto [OR, 0,97]). I risultati indicano che i tassi di mortalità in ospedale sono generalmente più alti negli uomini che nelle donne, dopo essere stati adeguati alla gravità della malattia. Inoltre, il rischio di morte in ospedale in uomini e donne è influenzato dalla diagnosi. Queste differenze possono riflettere variazioni di genere nell'utilizzo dei servizi ospedalieri, nell'efficacia delle cure, nell'eccesso o nella sottovalutazione della gravità della malattia o essere legate alle differenze biologiche caratterizzanti i due sessi.

Lo studio di Akbar ha mostrato che i maschi diabetici sono ad aumentato rischio di ammalarsi di CAP rispetto alle donne diabetiche, mentre questo non era così evidente tra maschi e femmine non diabetici. ${ }^{8}$ Per determinare gli organismi causali, la suscettibilità antimicrobica e l'esito della polmonite acquisita in comunità e in ospedale nei diabetici e confrontare questo con i non diabetici, le colture di espettorato eseguite all'ospedale universitario King Abdulaziz nel periodo tra gennaio 1998 e dicembre 1999 sono state riviste. Sono stati studiati in totale 354 casi, di cui 125 (35\%) erano diabetici. I pazienti diabetici, rispetto ai non diabetici, erano più anziani con una predominanza maschile. Haemophilus influenzae è stato l'agente patogeno più comune nella CAP sia nei diabetici che nei non diabetici; c'era, inoltre, una predominanza di Staphylococcus aureus nei diabetici rispetto ai non diabetici. I bacilli gram-negativi erano i patogeni più comuni nella polmonite acquisita in ospedale (HAP), sia nella popolazione diabetica che non diabetica. Nessuna differenza significativa nella mortalità è stata trovata tra diabetici e non diabetici, sia per CAP che per HAP, ma il sesso maschile era un predittore di outcomes peggiori in termini di durata di ospedalizzazione, decorso clinico e mortalità. ${ }^{8}$

È interessante notare che più donne sono state arruolate e/o ricoverate in ospedale negli studi condotti su pazienti con casi più lievi di CAP..$^{9,10}$

Per quanto riguarda le NHAP (Nursing home-acquired pneumonia) tre studi sono disponibili per i residenti delle case di riposo. ${ }^{11-13}$ Due di questi studi ${ }^{11,12}$ hanno riportato che il sesso maschile era un fattore di rischio per lo sviluppo di NHAP e il terzo studio ha riportato che $\mathrm{i}$ maschi erano più comunemente ospedalizzati per questa condizione. ${ }^{13}$

Diversi gli studi ${ }^{14-23}$ che interessano le polmoniti nosocomiali (NP) hanno esaminato i fattori associati 
allo sviluppo e agli outcomes delle NP. In quasi tutti, la NP si è sviluppata più frequentemente negli uomini: diversi studi hanno anche riportato che il sesso maschile era un fattore di rischio per lo sviluppo di NP. Lo studio di Arozullah e colleghi ${ }^{18}$ è stato condotto negli ospedali militari e pertanto ha arruolato il $98 \%$ degli uomini. Il rapporto maschi-femmine per quanto riguarda le polmoniti nosocomiali in questo studio era di 2,19. È interessante notare che i risultati di un solo studio $^{20}$ erano esattamente l'opposto; il sesso femminile era il fattore di rischio per lo sviluppo di NP. Inoltre, due studi ${ }^{17,19}$ che hanno analizzato i predittori di mortalità in pazienti con NP hanno riferito che il sesso femminile era un fattore di rischio indipendente per la mortalità.

Nell'analisi di Caceres et al. ${ }^{24}$ l'obiettivo era di valutare l'associazione tra genere ed outcomes clinici in pazienti ricoverati in terapia intensiva (ICU) con polmonite acquisita in ospedale (HAP) poiché i dati fino ad ora sono stati controversi. Lo studio concludeva che nei pazienti in terapia intensiva con polmonite, il genere femminile non era associato ad esiti peggiori né ad un aumento dell'utilizzo delle risorse rispetto al genere maschile. Gli autori aggiungevano la necessità di ulteriori studi per valutare gli outcomes nelle donne con polmonite in fase post-menopausale.

Per quanto riguarda la polmonite associata al ventilatore (VAP), diversi studi ${ }^{25-32}$ sono stati progettati per identificare i fattori associati allo sviluppo della VAP e i dati disponibili suggeriscono che i maschi sviluppano VAP più frequentemente rispetto alle femmine. Alcuni di questi studi hanno anche riportato che il sesso maschile era un fattore di rischio per la VAP. Sfortunatamente, non sono disponibili dati riguardanti la gravità della VAP (in termini di mortalità o durata dell'ospedalizzazione dovuta alla VAP) in relazione al sesso.

Per la polmonite da aspirazione (AP), il ruolo del sesso è stato studiato in diverse popolazioni di pazienti (pazienti con ictus, pazienti sottoposti a chirurgia). ${ }^{33-35}$

Tutti questi studi hanno concluso che il sesso maschile è un fattore di rischio per lo sviluppo di AP.

\section{Infezioni delle vie respiratorie: possibili meccanismi esplicativi delle differenze osservate}

Diversi fattori possono avere un ruolo nello sviluppo delle infezioni delle vie respiratorie. ${ }^{1}$ Certamente le differenze anatomiche del tratto respiratorio possono parzialmente spiegare la diversa prevalenza di infezioni tra maschi e femmine. In particolare, le femmine hanno seni paranasali più piccoli e quindi possono essere più suscettibili alla sinusite. ${ }^{36} \mathrm{D}$ 'altro canto, la pneumatizzazione del processo mastoideo può spiegare le infezioni dell'orecchio più frequenti e gravi nei bambini maschi. ${ }^{37} \mathrm{C}^{\prime}$ è anche evidenza che le vie aeree periferiche sono sproporzionatamente più strette durante $i$ primi anni di vita nei maschi, cosa che può predisporre alle infezioni delle basse vie respiratorie..$^{38}$

Diversi fattori socioeconomici e comportamentali, inoltre, giocano verosimilmente un ruolo nello sviluppo delle RTI e possono parzialmente spiegare le differenze osservate. ${ }^{39}$ Una percentuale significativa di donne svolge lavori a basso reddito, part-time, che non forniscono l'assicurazione sanitaria. Inoltre, molte donne perdono la loro assicurazione sanitaria dopo il divorzio o la morte del marito. Le prove disponibili suggeriscono che attualmente quasi un terzo delle famiglie con capofamiglia donna negli Stati Uniti vive in povertà; e la frazione è più alta per le donne afroamericane e le donne di origine latina. ${ }^{40}$ Queste differenze economiche possono o spiegare le variazioni osservate nello sviluppo di RTI o dare luogo a false conclusioni. Nel primo caso, l'accesso all'assistenza sanitaria è limitato per le donne che vivono in povertà e quindi la probabilità di iscriversi agli studi diventa minore. Nel secondo caso, la povertà è associata a scarsa igiene, scarsa conoscenza e mancato accesso alla prevenzione delle malattie (vaccinazione e trasmissione) e quindi maggiore probabilità di esposizione a microrganismi infettivi. ${ }^{1}$

Inoltre, il fumo è un'abitudine più comune nei maschi, sebbene la prevalenza nelle donne aumenti progressivamente ${ }^{41-43} \mathrm{Il}$ fumo è associato a diverse malattie delle vie respiratorie che predispongono alle infezioni; infatti il fumo attiva un processo che distrugge l'epitelio delle vie aeree superiori, condizione che elimina la fisiologica clearance di potenziali patogeni.

Ulteriori spiegazioni di questi risultati possono essere trovate nella differente percezione della gravità della malattia tra maschi e femmine. Le donne possono cercare più facilmente assistenza sanitaria per le malattie lievi, come la tonsillite e la faringite, che possono spiegare la maggiore prevalenza di queste malattie nelle femmine. Inoltre, esse tendono tradizionalmente a trascorrere più tempo rispetto agli uomini con i loro figli, esponendosi così alle infezioni virali comuni nei bambini. ${ }^{1}$

Un'attenzione particolare dovrebbe essere rivolta alle differenze biologiche e principalmente agli ormoni sessuali. Gli ormoni sessuali steroidei sono responsabili di una varietà di azioni durante l'attivazione del sistema immunitario. In generale, si ritiene che gli estrogeni a concentrazioni fisiologiche svolgano un ruolo di stimolazione immunitaria sovraregolando l'immunità cellulare e umorale, mentre gli androgeni hanno un impatto anti-infiammatorio. ${ }^{44}$ La maggior parte dei dati disponibili su questo problema proviene da pazienti con malattie autoimmuni. In entrambi i sessi, gli ormoni surrenali, ossia glucocorticoidi, deidroepiandrosterone (DHEA) ed androgeni, sono inadeguatamente bassi nei 
pazienti con malattie autoimmuni rispetto ai controlli sani. ${ }^{45}$ Inoltre, come abbiamo visto in precedenza, gli animali femmine sembrano avere una risposta immunitaria più vigorosa. ${ }^{40}$ Infine, la somministrazione di 17 $\beta$-estradiolo stabilizza o aumenta la secrezione, indotta da stimoli immunitari, di TNF, IL-2, IL-4, IL-6, IL-10 e IFN $\gamma$ da parte dei leucociti del sangue periferico di maschi sani. Il testosterone, al contrario, inibisce (IL2, IL-4, IL-10) o tende ad inibire la secrezione di queste citochine (TNF, IFN $\gamma){ }^{44}$

Sebbene queste differenze per quanto concerne gli ormoni sessuali circolanti possano spiegare, almeno in parte, le differenze riportate nell'incidenza e nella gravità degli RTI tra uomini e donne, le differenze tra maschi e femmine in età infantile rimangono senza risposta, dal momento che il ruolo e la concentrazione degli ormoni sessuali non sono così significative nei primi anni di vita.

Un'altra considerazione da fare, che potrebbe mettere in discussione quanto detto sopra, è che molte malattie croniche, come il diabete mellito o le malattie autoimmuni, e condizioni croniche, come l'obesità, che compromettono la funzione del sistema immunitario sono più comunemente presenti nelle donne. ${ }^{1}$

Di fatto a tutt'oggi sono necessari studi specifici al fine di ottenere evidenze scientifiche, che consentano di spiegare e comprendere le differenze di genere nelle infezioni delle vie respiratorie ed in particolare delle polmoniti.

\section{Bibliografia}

1. Falagas ME, Mourtzoukou EG, Vardakas KZ. Sex differences in the incidence and severity of respiratory tract infections. Respir Med. 2007;101:1845-63.

2. Crabtree TD, Pelletier SJ, Gleason TG. et al. GenderDependent Differences in Outcome After the Treatment of Infection in Hospitalized Patients. JAMA 1999;282: 2143-2148

3. Wichmann MW, Inthorn D, Andress HJ, et al. Incidence and mortality of severe sepsis in surgical intensive care patients: the influence of patient gender on disease process and outcome. Intensive Care Med. 2000; 26:167-72.

4. Schröder J, Kahlke V, Staubach KH, et al. Gender differences in human sepsis. Arch Surg, 1998;133:1200-5.

5. Cabello N, Mishra V, Sinha U, et al. Sex differences in the expression of lung inflammatory mediators in response to ozone. Am J Physiol Lung Cell Mol Physiol. 2015;15:1150-63.

6. Kaplan V, Angus DC, Griffin MF, et al. Hospitalized community-acquired pneumonia in the elderly: Age and sex-related patterns of care and outcome in the United States American Journal of Respiratory and Critical Care Medicine 2002;165:766-772.

7. Gordon HS, Rosenthal GE. The relationship of gender and in-hospital death: Increased risk of death in men. Medical Care 1999;37:318-324.
8. Akbar DH. Bacterial pneumonia: Comparison between diabetics and non-diabetics. Acta Diabetologica 2001; 38:77-82.

9. Marrie TJ, Huang JQ. Low-risk patients admitted with community-acquired pneumonia. Am J Med. 2005; 118:1357-1363.

10. Aliyu ZY, Aliyu MH, McCormick K. Determinants for hospitalization in "low-risk" community acquired pneumonia. BMC Infect Dis 2003;3:11.

11. Sund-Levander M, Ortqvist A, Grodzinsky E, et al. Morbidity, mortality and clinical presentation of nursing home-acquired pneumonia in a Swedish population. Scand J Infect Dis 2003;35:306-310.

12. Loeb M, McGeer A, McArthur M, et al. Risk factors for pneumonia and other lower respiratory tract infections in elderly residents of long-term care facilities. Arch Intern Med 1999;159:2058-2064.

13. Hutt E, Ecord M, Eilertsen TB, et al. Precipitants of emergency room visits and acute hospitalization in short-stay medicare nursing home residents. J Am Geriatr Soc 2002;50:223-229.

14. Sopena N, Sabria M, Neunos. 2000 Study Group Multicenter study of hospital-acquired pneumonia in nonICU patients. Chest 2005; 127:213-219.

15. Gastmeier P, Sohr D, Geffers C, et al. Mortality risk factors with nosocomial Staphylococcus aureus infections in Intensive Care Units: results from the German Nosocomial Infection Surveillance System (KISS). Infection 2005;33:50-55.

16. Lee SC, Hua CC, Yu TJ, et al. Risk factors of mortality for nosocomial pneumonia: importance of initial antimicrobial therapy. Int J Clin Pract 2005;59:39-45.

17. Napolitano LM, Greco ME, Rodriguez A, et al. Sex differences in adverse outcomes after blunt trauma. J Trauma 2001;50:274-280.

18. Arozullah AM, Khuri SF, Henderson WG, et al. Participants in the National Veterans Affairs Surgical Quality Improvement Program. Development and validation of a multifactorial risk index for predicting postoperative pneumonia after major noncardiac surgery. Ann Intern Med 2001;135:847-857.

19. Crabtree TD, Pelletier SJ, Gleason TG, et al. Sex-dependent differences in outcome after the treatment of infection in hospitalized patients JAMA 1999;282:2143-2148.

20. Gomez J, Esquinas A, Agud MD, et al. Retrospective analysis of risk factors and prognosis in non-ventilated patients with nosocomial pneumonia. Eur J Clin Microbiol Infect Dis 1995;14:176-181.

21. Vanhems P, Lepape A, Savey, et al. Nosocomial pulmonary infection by antimicrobial-resistant bacteria of patients hospitalised in intensive care units: risk factors and survival. J Hosp Inf. 2000;45:98-106.

22. Kropec A, Schulgen G, Just H, et al. Scoring system for nosocomial pneumonia in ICUs. Intensive Care Med. 1996;22:1155-1161.

23. Carratala J, Gudiol F, Pallares R, et al. Risk factors for nosocomial Legionella pneumophila pneumonia. Am J Respir Crit Care Med. 1994;149:625-629.

24. Caceres F, Welch VL, Kett DH, et al. Absence of gender-based differences in outcome of patients with hospital-acquired pneumonia. J Womens Health (Larchmt) 2013;22:1069-75.

25. Shorr AF, Duh MS, Kelly KM, et al. Red blood cell 
transfusion and ventilator-associated pneumonia: a potential link? Crit Care Med 2004;32:666-674.

26. Bornstain C, Azoulay E, De Lassence A, et al. Sedation, sucralfate, and antibiotic use are potential means for protection against early-onset ventilator-associated pneumonia. Clin Infect Dis 2004;38:1401-1408.

27. Rello J, Ollendorf DA, Oster G, et al. Outcomes Scientific Advisory Group Epidemiology and outcomes of ventilator-associated pneumonia in a large US database. Chest 2002;122:2115-2121.

28. Cook DJ, Walter SD, Cook RJ, et al. Incidence of and risk factors for ventilator-associated pneumonia in critically ill patients. Ann Intern Med 1998,129:433-440.

29. Kollef MH, Von Harz B, Prentice D, et al. Patient transport from intensive care increases the risk of developing ventilator-associated pneumonia. Chest,1997;112: 765-773.

30. Papazian L, Bregeon F, Thirion X, et al. Effect of ventilator-associated pneumonia on mortality and morbidity. Am J Respir Crit Care Med 1996;154:91-97.

31. Rello J, Ausina V, Ricart M, et al. Prats Impact of previous antimicrobial therapy on the etiology and outcome of ventilator-associated pneumonia. Chest 1993;104: 1230-1235.

32. Rello J, Ricart M, Ausina V, et al. Prats Pneumonia due to Haemophilus influenzae among mechanically ventilated patients. Incidence, outcome, and risk factors. Chest 1992;102:1562-1565.

33. Isbister GK, Downes F, Sibbritt D, et al. Whyte Aspiration pneumonitis in an overdose population: frequency, predictors, and outcomes. Crit Care Med 2004;32:88-93.

34. Aslanyan S, Weir CJ, Diener HC, et al. GAIN International Steering Committee and Investigators Pneumonia and urinary tract infection after acute ischaemic stroke: a tertiary analysis of the GAIN International trial. Eur J Neurol 2004;11:49-53.

35. Kozlow JH, Berenholtz SM, Garrett E, et al. Epidemiology and impact of aspiration pneumonia in patients undergoing surgery in Maryland, 1999-2000. Crit Care Med 2003;31:1930-1937.
36. Chen Y, Dales R, Lin M. The epidemiology of chronic rhinosinusitis in Canadians. Laryngoscope 2003; 113:1199-205.

37. Apostolopoulos K, Xenelis J, Tzagaroulakis A, et al. The point prevalence of otitis media with effusion among school children in Greece. Int J Pediatr Otorhinolaryngol 1998;44:207-14.

38. Gupta R, Helms PJ, Jolliffe IT, et al. Seasonal variation in sudden infant death syndrome and bronchiolitis-a common mechanism? Am J Respir Crit Care Med 1996; $154: 431-5$

39. Cohen S. Social status and susceptibility to respiratory infections. Ann NW Acad Sci 1999;896:246-53.

40. Komaroff AL, Robb-Nicholson C, Dunaif AE. Women's health. In: Harrison's principles of internal medicine, 15th ed, vol. 1. New York; Maidenhead, UK: McGrawHill, 2001. p. 21-5.

41. MacDonald S, Joffres MR, Stachenko S, et al. Multiple cardiovascular disease risk factors in Canadian adults.Canadian Heart Health Surveys Research Group. Can Med Assoc J 1992;146:2021-9.

42. Lahti-Koski M, Pietinen P, Heliovaara M, et al. Associations of body mass index and obesity with physical activity, food choices, alcohol intake, and smoking in the 1982-1997 FINRISK Studies 1-3. Am J Clin Nutr 2002;75:809-17.

43. Haenle MM, Brockmann SO, Kron M, et al. Overweight, physical activity, tobacco and alcohol consumption in a cross-sectional random sample of German adults. BMC Publ Health 2006;6:233.

44. Janele D, Lang T, Capellino S, et al. Effects of testosterone, 17beta-estradiol, and downstream estrogens on cytokine secretion from human leukocytes in the presence and absence of cortisol. Ann NY Acad Sci 2006; 1069:168-82.

45. Schmidt M, Naumann H, Weidler C, et al. Inflammation and sex hormone metabolism. Ann NY Acad Sci 2006;1069:236-46. 


\title{
Le principali malattie respiratorie in ottica di genere dall'epidemiologia alla diagnosi e alla terapia: tromboembolia polmonare
}

\author{
Mariagrazia Porru, ${ }^{1}$ Paola Pitto ${ }^{2}$ \\ ${ }^{1}$ UO Medicina Interna ed Emocoagulopatie, Policlinico Universitario Duilio Casula, Università di Cagliari; \\ ${ }^{2}$ Medicina Generale, Ospedale di Sestri Levante, ASL 4 Chiavarese, Sestri Levante (GE), Italia
}

\section{Epidemiologia e fattori di rischio}

Il tromboembolismo venoso (TEV), che include la trombosi venosa profonda (TVP) e l'embolia polmonare (EP), è una malattia dell'età avanzata con un'incidenza annuale, secondo dati americani, di 117 per 100.000 anni-persona tra i caucasici. L'incidenza globale aggiustata per età e sesso è più alta negli uomini (130 eventi per 100.000 soggetti a rischio) che per le donne (110 per 100.000) con un rapporto maschi/femmine di 1,2:1. ${ }^{1}$ Durante l'età fertile, i tassi di incidenza nelle donne sono un po' più alti se comparati con uomini della stessa età per la differente esposizione a fattori di rischio estrinseci come estroprogestinici, gravidanza e puerperio. Dopo i 45 anni invece, l'incidenza è maggiore negli uomini. Recentemente, sono stati pubblicati i dati di uno studio epidemiologico italiano condotto in Piemonte e Lombardia su una popolazione di 13 milioni di persone in cui venivano identificati tramite $\mathrm{i}$ codici di patologia internazionali (ICD-9-CM) i pazienti dimessi con una diagnosi di EP tra il 2002 e il 2012. I risultati mostrano che l'incidenza della patologia nel periodo esaminato è stata di 55,4 casi ogni 100.000 abitanti nelle donne e 40,6 casi ogni 100.000 negli uomini. Dopo aver aggiustato il dato per l'età della popolazione la differenza di incidenza per sesso è venuta meno. ${ }^{2}$ Questo perché l'epidemiologia di ciascuna malattia varia in base alle popolazioni prese

\footnotetext{
Corrispondente: Mariagrazia Porru, UO Medicina Interna ed Emocoagulopatie, Policlinico Universitario Duilio Casula, Università di Cagliari, Italia.

Tel.: +39.070.51096119.

E-mail: mariagraporru@gmail.com

Articolo pubblicato secondo la Creative Commons Attribution NonCommercial 4.0 License (CC BY-NC 4.0).

CCopyright M. Porru e P. Pitto, 2019

Licensee PAGEPress, Italy

QUADERNI - Italian Journal of Medicine 2019; 7(2):21-27
}

in esame. Oggi è dato da tutti per scontato che la donna, con una prima trombosi venosa non correlata a fattori di rischio riproduttivi, ha un rischio all'incirca dimezzato rispetto all'uomo di sviluppare recidive tromboemboliche. La metanalisi di Douketis et al. ${ }^{3}$ di sette studi prospettici e 2554 pazienti affetti da un primo episodio di TEV, osservati durante un follow-up di 27,1 mesi e per i quali veniva valutata un'associazione tra D-dimero, dopo la sospensione della terapia anticoagulante, e la recidiva del tromboembolismo venoso, ha ulteriormente confermato questi dati.

La ragione per cui gli uomini hanno un rischio doppio di trombosi venosa ricorrente rispetto alle donne è ancora sconosciuta.

Questo implica che tutti i modelli, che negli ultimi anni sono stati proposti per stratificare il rischio di recidiva dopo il primo episodio di TEV idiopatico, assegnino un punteggio più alto al genere maschile. Uno di questi modelli, ottenuto dalla forte collaborazione di diversi Centri in Italia, chiamato DASH score, insieme alla misurazione del D-dimero a 3-5 settimane dalla sospensione della terapia anticoagulante, l'età sotto i 50 anni e l'utilizzo di estroprogestinici al momento dell'evento indice, include il sesso maschile come predittore indipendente di trombosi venosa ricorrente. ${ }^{4}$ Lo score, la cui validità è stata poi successivamente confermata soprattutto nei soggetti di età inferiore ai 65 anni, nella pratica clinica aiuta a sostenere strategie terapeutiche differenti tra gli uomini e le donne che hanno subíto un primo evento trombotico venoso. ${ }^{5}$ Infatti, quando il punteggio ottenuto è uguale o inferiore a uno, il rischio annuale di recidiva dopo una trombosi idiopatica è sotto il $5 \%$ e dopo sei mesi il trattamento anticoagulante può quindi essere interrotto con ragionevole sicurezza.

Recentemente è stato mostrato che quando si escludono dal computo gli eventi trombotici specifici del genere femminile perché legati ad ormoni, gravidanza e parto, anche il rischio del primo episodio trombotico venoso appare all'incirca due volte superiore nell'uomo rispetto alla donna. ${ }^{6}$ Esattamente come capita per il rischio di recidiva. 
Una diversa genetica nel rischio di trombosi venosa tra uomini e donne è plausibile perché in questo lavoro, che ha analizzato i dati dello studio MEGA, la differenza di rischio si vede bene nel giovane maschio quasi a voler sottolineare che l'uomo (che in giovane età è meno esposto a fattori di rischio per TEV legati all'età avanzata) ha fattori di rischio per sè che ovviamente ancora non sono conosciuti. In alternativa differenze acquisite e legate al diverso stile di vita tra uomo e donna possono essere considerate.

Nel 1884 il patologo tedesco Virchow affermava che la trombosi deriva dall'interazione di tre fattori: danno endoteliale, stasi venosa ed ipercoagulabilità. Non esiste una condizione trombotica senza questi fattori di rischio che intervengono a diversi livelli della triade con un valore predittivo differente a seconda dei quali vengano presi in considerazione. Infatti in base al loro grado di associazione tra la loro presenza e l'insorgenza di TEV, possono essere stratificati in fattori di rischio deboli con odds ratio $(\mathrm{OR})<2$ come: età avanzata, obesità, allettamento per più di tre giorni, chirurgia laparoscopica, gravidanza, oppure intermedi (OR 2-9): cancro, chemioterapia, scompenso cardiaco o respiratorio, trombofilia, storia clinica di TEV, estroprogestinici, puerperio o ancora più importanti (OR $>10$ ) quali: chirurgia generale maggiore (ortopedica, oncologica, neurochirurgica) e traumi maggiori. ${ }^{7}$

Nel genere femminile, estroprogestinici, terapia ormonale sostitutiva, gravidanza e puerperio (periodo di tempo che comprende le sei settimane dopo il parto) rappresentano fattori di rischio aggiuntivo per TEV.

Il rischio di TEV nelle donne che assumono estroprogestinici è basso (1:1000 per anno) e aumenta da 2 a 4 volte rispetto a chi non li assume. ${ }^{8}$ La diversa combinazione di estrogeni e progestinici conferisce un rischio differente di TEV. Questo dato deve essere preso in forte considerazione quando decidiamo di prescriverli valutando accuratamente la storia clinica precedente e la familiarità per TEV al di là di uno screening trombofilico. Un contenuto di estrogeni pari a $30 \mathrm{mg}$ di etinilestradiolo, conferisce un rischio trombotico maggiore rispetto a $20 \mathrm{mg} .{ }^{9}$ Inoltre, a seconda dei progestinici associati, questo rischio è ancora diverso e ridotto se si considerano quelli di seconda generazione come il levonorgestrel, rispetto a desogestrel, gestodene o drospirenone che sono di terza generazione. ${ }^{10}$ Vie di somministrazione diverse da quella orale come cerotti transdermici e anelli vaginali conferiscono comunque un rischio trombotico aumentato rispettivamente di quasi otto e sei volte e mezzo rispetto a chi non ne fa uso. ${ }^{11}$ Lidegaard, massimo esperto di trombosi venosa, suggerisce che per donne con rischio trombotico di base (età $>35$ anni, obesità, fumo di sigaretta) deve essere considerata come prima scelta l'utilizzo del solo progestinico in pillola o come device intrauterino che non conferisce un aumento ulteriore di tale rischio, mentre in donne sane e al di sotto dei 35 anni l'estroprogestinico ideale è quello a bassa dose di estrogeno $(15-20 \mathrm{mg})$ combinato con un progestinico di seconda generazione. ${ }^{12}$

Il rischio di TEV in gravidanza è quattro volte più alto rispetto a donne non gravide inizialmente per via dei fenomeni che regolano l'impianto del trofoblasto nell'utero e più avanti per quelli che regolano il distacco della placenta. Questo rischio, in particolare di $E P$, è cinque volte più alto nel puerperio quando fenomeni coagulativi maggiori nel terzo trimestre di gravidanza, in particolare l'incremento dei fattori della coagulazione e la riduzione degli anticoagulanti naturali, persistono oltre il parto. ${ }^{13}$ Come per gli estroprogestinici, anche la gravidanza e il puerperio hanno azione sinergica con i difetti trombofilici acquisiti ed ereditari e per alcuni di questi, quali il deficit di antitrombina III, proteina $\mathrm{C}$ ed $\mathrm{S}$ che sono molto rari (prevalenza nella popolazione generale rispettivamente $\mathrm{di}$ $0,2,0,4$ e $0,1 \%),{ }^{14}$ il rischio assoluto di trombosi è elevato e sale in maniera veramente importante nel postpartum $(11,1,5,4$ e $4,2 \%)$, rispetto al periodo precedente $(7,3,3,2$ e $0,9 \%$ rispettivamente) $) .{ }^{15}$

In letteratura, al momento, non per tutti i fattori di rischio di TEV esistono differenze di genere.

L'obesità centrale $\left(B M I \geq 30 \mathrm{~kg} / \mathrm{m}^{2}\right)$, fattore di rischio per TEV noto ormai da anni sia nell'uomo che nella donna, incrementa di due volte il rischio di trombosi rispetto ai non-obesi perché in questa condizione è maggiore la formazione di trombina ed è ridotta la fibrinolisi. Questi dati sono anche confermati dall'analisi retrospettiva del database NHDS (National Hospital Discharge Survey) di soggetti ospedalizzati della Columbia (1979-1999) dove considerando più precisamente l'età degli obesi e il genere maschile $\mathrm{o}$ femminile, si vede come nelle donne sopra i 70 anni rispetto a uomini della stessa età il rischio di EP è di poco maggiore, mentre nelle donne in giovane età $(<40$ anni) il rischio di TVP è addirittura doppio rispetto agli uomini coetanei. ${ }^{16}$ Ecco perché va incoraggiato il calo ponderale soprattutto in previsione di una gravidanza o prima di assumere gli estroprogestinici o in presenza di altri fattori di rischio quali mutazioni trombofiliche che non possiamo correggere.

Severinsen et al. ${ }^{17}$ hanno indagato il legame tra fumo di sigaretta e TEV in giovani uomini e donne in un sottogruppo del Diet Cancer and Health, studio prospettico di coorte, iniziato nel 1993 con lo scopo di valutare il ruolo della dieta nei soggetti con cancro e che ha preso in considerazione soggetti fumatori. L'associazione era stata valutata per TEV idiopatico e secondario e per EP e TVP. Il consumo di tabacco era in $\mathrm{gr} /$ die $(1$ grammo di tabacco $=1$ sigaretta). È risultata un'associazione positiva tra fumo e TEV in uomini e donne di mezza età che fumano [hazard ratio (HR) 1,52 nell'uomo e 1,32 nella donna]. E se nella donna l'asso- 
ciazione era presente per tutte le dosi di tabacco, nell'uomo questo era vero a partire da dosi sopra i $15 \mathrm{~g} /$ die. La donna forte fumatrice ( $>$ di 25 sigarette/die) ha, inoltre, un rischio di subire un EP più alto rispetto all'uomo a parità di dose di tabacco $(\mathrm{HR}, 2,95$ nella donna e 0,78 nell'uomo). Questa differenza non è dimostrata, invece, per un consumo di sigarette inferiore.

Nel 2001 Heit et al..$^{18}$ hanno stimato l'incidenza di TEV in ospedalizzati e residenti in comunità dell'Olmsted County trovando che questa è 100 volte più alta nei primi rispetto ai secondi e negli anziani. Inoltre durante il ricovero il numero degli uomini con trombosi venosa era quasi doppio rispetto alle donne $(1,9: 1)$. Un lavoro successivo, che ha considerato i dati del NHDS dal 1979 al 1999, ha mostrato che nei due generi l'incidenza di EP e TVP in pazienti ospedalizzati è quasi identica. ${ }^{19}$

La provata efficacia della profilassi antitrombotica, senza incremento significativo del sanguinamento maggiore nei pazienti ricoverati ad alto rischio, si scontra ancora con la difficoltà di una sua estensiva applicazione nella pratica clinica. ${ }^{20}$ Il Padua Prediction Score, nato da uno studio italiano del 2010 di Barbar et al. ${ }^{21}$ è il modello clinico da utilizzare in corsia per calcolare il rischio trombotico dei pazienti ricoverati. Questo modello, accettato anche dagli estensori delle linee guida ACCP, guida la prescrizione della profilassi anti trombotica nei reparti di degenza e non considera tra $\mathrm{i}$ criteri di rischio il genere maschile o femminile.

\section{Sintomatologia}

L'EP è la prima manifestazione di TEV più frequente nella donna, mentre nell'uomo prevale la TVP.

Scheres et al. hanno recentemente analizzato la tipologia di presentazione tromboembolica (TVP, EP con o senza TVP o EP da sola) secondo i dati che derivano da tre autorevoli fonti: studio MEGA, ampio studio caso-controllo che include 4953 soggetti con primo episodio di TEV, Hokusai VTE, studio internazionale di 6720 pazienti, che compara eparina/edoxaban con eparina/warfarin in TVP acuta e EP acuta sintomatiche e i dati del registro multicentrico RIETE che comprende oltre 40.000 pazienti con primo episodio di TEV. ${ }^{22} \mathrm{Nei}$ tre lavori, la maggiore rappresentazione di TEV come EP era osservata nelle donne $(+6 \%,+10 \%$ e $+5,6 \%$ rispettivamente) a tutte le età e con differenze maggiori tra i 30 e i 45 anni e sopra i 60 anni. Poiché la differenza è più pronunciata quando il confronto si esegue tra individui con TEV idiopatico, ne consegue che il fatto che la donna subisca più frequentemente una modalità di presentazione embolica, non è imputabile a fattori di rischio estrinseci propri del genere femminile, ma al genere femminile stesso. Inoltre anche la spiegazione di questo fenomeno è ancora del tutto sconosciuta.
I dati del registro internazionale ICOPER (International Cooperative Pulmonary Embolism Registry) ${ }^{23}$ mostrano che gli uomini con EP esordiscono più frequentemente con dolore toracico ed emottisi, mentre le donne hanno più spesso la dispnea. Quest'ultimo sintomo secondo Deng et al. ${ }^{24}$ che hanno osservato 149 pazienti giunti in Pronto Soccorso, era invece più frequentemente lamentato dagli uomini, ma l'esiguità del campione rispetto all'altro di 2454 pazienti non consente un confronto adeguato tra i dati.

L'EP è la responsabile di circa il $25 \%$ delle sincopi di cui non sia nota la causa, come afferma lo studio italiano di Prandoni et al. ${ }^{25}$ Sono le donne ad esordire maggiormente con sincope quando subiscono un' $\mathrm{EP}^{26} \mathrm{e}$ ad avere un'emodinamica instabile che può causare la perdita di coscienza.

La proporzione di TVP prossimale associata ad EP è più alta negli uomini che nelle donne $(43 \%$ vs $33 \%$; $\mathrm{P}=0,009)^{27}$ e il meccanismo sottostante questa differenza sesso-correlata non è stata chiarita.

Bisogna ricordare quindi che il sospetto clinico di EP deve essere formulato anche in assenza di segni clinici di TVP in tutti i pazienti e con un'attenzione maggiore se si tratta di donne che possono non avere una trombosi periferica e che, come già detto in precedenza, esprimono maggiormente il tromboembolismo venoso come EP. Lo score di Wells ${ }^{28}$ predittivo di EP, considera vari fattori (storia clinica positiva per TEV, tachicardia, recente chirurgia o immobilizzazione, clinica di TVP, diagnosi alternativa, emottisi, neoplasia), ma non il genere femminile di cui noi possiamo invece tenerne conto nella nostra attività quotidiana.

\section{Comorbidità}

Il TEV clinicamente evidente si associa a una neoplasia attiva nel $15-20 \%$ circa dei casi definita come preesistente o che viene diagnosticata durante i tre mesi successivi alla diagnosi di trombosi. ${ }^{29}$ Una EP o TVP possono essere la prima manifestazione di una neoplasia occulta nel $2-10 \%$ dei casi entro il primo anno dalla diagnosi del tumore. ${ }^{30}$ Predittori clinici per una nuova diagnosi di cancro dopo TEV, sono l'età avanzata $(\mathrm{HR}, 1,23)$ e l'evento trombotico venoso non provocato (HR, 1,86), mentre il genere maschile o femminile non ha alcun impatto sul rischio di una nuova diagnosi di neoplasia. ${ }^{31}$

Secondo alcuni autori comunque l'associazione tra EP e cancro è maggiore nell'uomo. ${ }^{24,26,32}$ Nella recente analisi retrospettiva del database NIS (National Inpatient Sample) condotta da Marshall et al. sia i tumori solidi che le metastasi sono, invece, di più nelle donne con diagnosi concomitante di EP. ${ }^{33}$ Il trattamento chemioterapico aumenta il rischio trombotico e quindi una profilassi con anticoagulanti deve essere effettuata quando il Khorana score è $\geq 3 .{ }^{34}$ In questo modello de- 
rivato da 2701 pazienti e validato in un'ampia coorte di 1365 con varie neoplasie, il genere maschile o femminile non è risultato statisticamente significativo tra i vari predittori di TEV e quindi non viene considerato nel calcolo del rischio trombotico.

L'analisi dei registri e database attualmente disponibili, permette di ricavare solo alcune informazioni in un'ottica di genere sulle comorbidità dei pazienti affetti da EP (Tabella 1).

La prevalenza di EP nella BPCO riacutizzata è del $19 \%$, ossia un quarto dei pazienti ricoverato per BPCO può avere l'EP. ${ }^{35}$ L'associazione tra BPCO ed EP acuta sintomatica, secondo la maggior parte dei lavori al momento presenti, è più frequente nell'uomo. ${ }^{23,24,26,32}$ Dal momento che però la BPCO è in aumento tra le donne, per le quali tra l'altro, il decadimento della funzione polmonare avviene in età più giovane e per un minor consumo di tabacco rispetto all'uomo, l'analisi retrospettiva del più numeroso database pubblico americano NIS mostra una maggiore associazione tra EP e genere femminile..$^{33} \mathrm{Il}$ rischio relativo di subire un' EP per un paziente affetto da scompenso cardiaco acuto è doppio rispetto a chi non ne soffre e aumenta con il declino della frazione di eiezione. ${ }^{36}$ Questo è vero in particolare per il genere femminile. ${ }^{23,32,33} \mathrm{Con}$ la diagnosi di insufficienza cardiaca spesso concomita quella di fibrillazione atriale che, seppur abbia un'incidenza maggiore nell'uomo, quando è associata ad EP è maggiore nella donna. ${ }^{23,32}$ Negli ultimi anni alcuni studi mettono in dubbio che le trombosi arteriose e venose siano del tutto estranee tra di loro. Questo non deve stupire se, del resto, fattori di rischio come la sindrome metabolica vedono coinvolte condizioni quali l'obesità comuni ad entrambe. L'analisi dello studio LITE (Longitudinal Investigation of Throm- boembolism Etiology), a cura di Steffen et al. ${ }^{37}$ mostra che la sindrome metabolica è associata ad un rischio totale di TEV idiopatico maggiore negli uomini rispetto alle donne [HR 1,59], probabilmente perché nel gruppo di pazienti considerati, l'obesità addominale era maggiore tra i primi [HR per TEV 2,10 negli uomini, HR per TEV 1,7 nelle donne].

\section{Valutazione prognostica e diagnosi}

Nelle attuali linee guida europee ${ }^{38}$ per la diagnosi ed il trattamento dell'EP, la classificazione clinica è basata sul livello di rischio di mortalità precoce, definita come mortalità intraospedaliera o a 30 giorni. Questa stratificazione (tramite lo score PESI e la versione semplificata sPESI) permette di distinguere tra $\mathrm{EP}$ ad alto rischio in presenza di shock o ipotensione persistente ed EP a non alto rischio. Gli score clinici, utilizzati per evitare indagini diagnostiche di secondo livello nei pazienti a basso rischio, nonostante le differenze di genere in molti aspetti della malattia, non ne tengono conto. ${ }^{39}$ Uno studio ${ }^{40}$ che ha analizzato gli eventi avversi a 30 giorni utilizzando i due score PESI e sPESI ha concluso che entrambi gli indici identificano bene i pazienti a basso rischio, ma sPESI tende a sovrastimare alcuni pazienti di questo gruppo, che quindi vengono sottoposti a ulteriori inutili indagini. Il fattore maschio, quindi, ha un suo peso in quanto, indirettamente, permette di introdurre la diversa tipologia di paziente (diverse comorbidità, età di presentazione, quadro clinico, variabili sociali). Nella valutazione prognostica il $\mathrm{D}$-dimero ha valore predittivo negativo ed è possibile avere un falso positivo in caso di neoplasia, ospedalizzazione, età avanzata e

Tabella 1. Embolia polmonare e comorbidità. Differenze di genere.

\begin{tabular}{lcccc}
\hline Comorbidità & Studio & Maschi (\%) & Femmine (\%) & P value \\
\hline BPCO & 29 & $52.490(20,6)$ & $65.870(23,1)$ & $<0,001$ \\
\hline 26 & $136(14)$ & $33(3)$ & $<0,001$ \\
\hline 27 & $23(32)$ & $2052(19)$ & $1318(10)$ & 0,023 \\
\hline Scompenso cardiaco & $175(16)$ & $134(10)$ & $<0,001$ \\
\hline Fibrillazione atriale & 32 & $839(7,6)$ & $1366(11)$ & $<0,001$ \\
\hline Sindrome metabolica & 28 & $25.980(10,2)$ & $31.255(11)$ & $<0,001$ \\
\hline Malattia renale & 29 & $88(8)$ & $163(12)$ & 0,002 \\
\hline Malattia epatica & 32 & $733(6,7)$ & $204(15)$ & $<0,001$ \\
\hline
\end{tabular}


gravidanza (tutte situazioni genere-specifiche). BNP e troponina sono markers clinici di disfunzione ventricolare destra e di danno miocardico nei quadri di shock e ipotensione, che sono di più frequente presentazione nelle donne. Per quanto riguarda la diagnostica, si ricorda che sebbene l'angio-TC sia il gold standard, nelle donne fertili e in gravidanza va preferita la scintigrafia ventilatoria-perfusionale per minore somministrazione di radiazioni. Alcuni studi retrospettivi, ${ }^{26,41}$ che hanno analizzato l'outcome dei pazienti, hanno evidenziato come anche le pazienti femmine emodinamicamente stabili presentino maggiore mortalità sia intraospedaliera che ad un mese dal ricovero verosimilmente per età più avanzata e comorbidità, ma anche per differenze nell'attività trombotica e fibrinolitica e per estensione della malattia a livello polmonare. Le donne, quindi, richiedono maggiore monitorizzazione, tempi di degenza più lunghi e maggiori risorse. Analizzando queste osservazioni nell'ottica di genere, ${ }^{42}$ si ipotizza che le donne tendano a rifiutare l'ospedalizzazione perché hanno maggiori responsabilità familiari e di caregiver, hanno maggiore conoscenza della propria salute, si informano di più e sono più attente, sono più propense a cercare e seguire i consigli del proprio medico, il che porta a diagnosi e trattamento precoce. Inoltre la ridotta ospedalizzazione può essere dovuta anche al misconoscimento di segni e sintomi attribuiti a stati ansiosi, specie in giovane età, o ad una maggiore presunzione di conoscenza della propria salute con ritardo sul timing diagnostico-terapeutico.

\section{Terapia}

Per quanto riguarda la terapia, le donne risultano essere soggette a maggior rischio di sanguinamento, anche con i NOACs ${ }^{43}$ per una differente farmacocinetica nei due sessi; in particolare: differente distribuzione del tessuto adiposo, diversa clearance della creatinina, differente volume di distribuzione, differente assorbimento farmacologico, diverso legame a proteine plasmatiche e differenze nell'escrezione urinaria. Spesso le donne affette sono obese e vengono sottoposte ad alte dosi di EBPM con osservazione più frequente di emorragie, specialmente ematomi, rispetto agli uomini. Nonostante il rischio emorragico, la donna allettata deve essere sottoposta a profilassi per il maggior rischio di TEP sia per il fattore di rischio età (periodo postmenopausale ovvero assenza dei fattori protettivi), sia per particolari e specifici periodi della vita procoagulanti (gravidanza, puerperio, utilizzo di terapia contraccettiva od ormonale sostitutiva o terapia con tamoxifene nella neoplasia mammaria). ${ }^{32}$ Uno studio ha analizzato l'incidenza di sanguinamento maggiore ${ }^{44}$ osservando che l'aggiustamento di dosaggio per peso corporeo è raccomandato solo per apixaban ed edoxaban ed infatti si riscontra minor rischio di sanguinamento nelle donne. Si è osservato, inoltre, che negli studi RE-LY (dabigatran), ENGAGE (edoxaban), ARISTOTLE (apixaban) e ROCKET (rivaroxaban) i pazienti che ricevevano concomitante terapia antiaggregante erano più frequentemente gli uomini, pertanto con maggior rischio di sanguinamento. Le donne vanno più frequentemente incontro a stroke perché non è chiaro se il farmaco alla dose corretta per peso abbia la stessa efficacia della dose piena. I NOACs presentano differenze tra loro in termini di meccanismo d'azione e farmacocinetica ovvero di sensibilità verso disfunzione renale, basso BMI, età avanzata e interazioni con altri farmaci. Fattori tutti che possono determinare indirettamente differenti effetti di genere. In un'altra metanalisi ${ }^{45}$ è stata sottolineata la difficoltà nell'analizzare i dati per il rischio di sanguinamento maggiore nelle donne in quanto si riscontrano in quest'ultime percentuali sensibilmente inferiori di pazienti sottoposte a terapia anticoagulante con NOACs. La letteratura è concorde circa la necessità di studi mirati in quanto, pur essendo evidenti le differenze di comportamento della malattia tromboembolica nei due sessi, di fatto non se ne conoscono le ragioni e le ipotesi avanzate sono basate su osservazioni retrospettive e su database finalizzati ad altre ricerche. Molte fonti di origine americana rimarcano la necessità di approfondimento della materia per via dei costi, decisamente più elevati per curare le donne a fronte, peraltro, di frequente insuccesso terapeutico. Conoscere le caratteristiche genere-specifiche alla base della patologia permetterebbe l'elaborazione di algoritmi più efficaci e sicuri.

\section{Conclusioni}

Il rischio del primo episodio trombotico venoso appare all'incirca due volte superiore nell'uomo rispetto alla donna.

Il genere maschile è anche il maggior determinante per il rischio di recidiva di tromboembolismo venoso e il rischio è doppio rispetto a quello femminile.

Fattori di rischio estrinseci aggiuntivi per la donna sono estroprogestinici, gravidanza e puerperio. L'uomo ha più frequentemente una neoplasia in atto o occulta.

Tra le comorbidità la BPCO è più frequente nell'uomo mentre nella donna sono lo scompenso cardiaco e la fibrillazione atriale.

Quando sviluppa un episodio trombotico venoso la donna, ha una probabilità più alta rispetto all'uomo di esordire con embolia polmonare in assenza di segni clinici di TVP che sono più comuni nell'uomo.

Per quanto riguarda la modalità di presentazione clinica l'uomo esordisce più frequentemente con il dolore toracico e l'emottisi mentre la donna con la sincope spesso legata all'instabilità emodinamica.

Le donne presentano infatti maggiore mortalità in- 
traospedaliera e a 30 giorni per età d'esordio più avanzata e comorbidità.

Le donne sono più soggette a sanguinamento maggiore, in corso di terapia, per differente farmacocinetica nei due sessi ma devono per contro essere sottoposte a profilassi per maggior rischio di EP.

In futuro sarà necessario identificare quali fattori, genetici o acquisiti, nell'uomo e nella donna, contribuiscono ad aumentare il rischio di tromboembolismo polmonare, così da poter stabilire, in maniera più accurata appropriati percorsi gestionali e terapeutici che tengano conto delle differenze di genere.

\section{Bibliografia}

1. Silverstein MD, Heit JA, Mohr DN, et al. Trend in the incidence of deep vein thrombosis and pulmonary embolism: a 25-years population-based study. Arch Intern Med 1998;158:585-93.

2. Dentali F, Ageno W, Pomero F, et al. Time trends and case fatality rate of in-hospital treated pulmonary embolism during 11 years of observation in Northwestern Italy. Thromb Haemost 2016;115:399-405.

3. Douketis J, Tosetto A, Marcucci M, et al. Risk of recurrence after venous thromboembolism in men and women: patient level meta-analysis. BMJ 2011;342:d813.

4. Tosetto A, Iorio A, Marcucci M, et al. Predicting disease recurrence in patients with previous unprovoked venous thromboembolism: a proposed prediction score (DASH). J Thromb Haemost 2012;10:1019-25.

5. Tosetto A, Testa S, Martinelli I, et al. External validation of the DASH prediction rule: a retrospective cohort study. J Thromb Haemost 2017;15:1963-70.

6. Roach REJ, Lijfering WM, Rosendaal FR, et al. Sex difference in risk of second but not of first venous thrombosis: paradox explained. Circulation 2014;129:51-6.

7. Anderson FA Jr, Spencer FA. Risk factors for venous thromboembolism. Circulation 2003;107:I-9-16.

8. De Bastos M, Stegeman BH, Rosendaal FR, et al. Combined oral contraceptives: venous thrombosis. Cochrane Database of Systematic Reviews 2014;3:CD010813.

9. Stegeman BH, De Bastos M, Rosendaal FR, et al. Different combined oral contraceptives and the risk of venous thrombosis: systematic review and network meta-analysis. BMJ 2013;347.

10. Vinogradova Y, Coupland C, Hippisley-Cox J. Use of combined oral contraceptives and risk of venous thromboembolism: nested case-control studies using the QResearch and CPRD database. BMJ 2015;350:h2135.

11. Lidegaard Ø, Nielsen LH, Wessel SC, Lokkegaard E. Venous thrombosis in users of non-oral hormonal contraception: follow-up study, Denmark 2001-10. BMJ 2012;344:2990.

12. Lidegaard Ø. Hormonal contraception, thrombosis and age. Expert Opin Drug Saf 2014;13:1353-60.

13. Heit JA, Kobbervig CE, James AH, Petterson TM, et al. Trend in the incidence of venous thromboembolism during pregnancy or postpartum: A 30-years populationbased study. Ann Intern Med 2005;143:697-706.

14. Mannucci PM, Franchini M. Classic thrombophilic gene variants. Thromb Haemost 2015;114:885-9.

15. Croles FN, Nasserinejad K, Duvekot JJ, et al. Pregnancy, thrombophilia, and the risk of a first venous thrombosis: systematic review and bayesian meta-analysis. BMJ 2017;359:j4452.

16. Stein PD, Beemath A, Olson RE. Obesity as a risk factor in venous thromboembolism. The American Journal of Medicine 2005;118:978-80.

17. Severinsen MT, Kristensen SR, Johnsen SP, et al. Smoking and venous thromboembolism: a Danish follow-up study. J Thromb Haemost 2009;7:1297-303.

18. Heit JA, Melton LJ 3rd, Lohse CM, et al. Incidence of venous thromboembolism in hospitalized patients vs community residents. Mayo Clin Proc 2001;76:1102-10.

19. Stein PD, Beemath A, Olson RE. Trends in the incidence of pulmonary embolism and deep vein thrombosis in hospitalized patients. Am J Cardiol 2005;95:1525-6.

20. Dentali F, Douketis JD, Gianni M, et al. Meta-analysis: anticoagulant prophylaxis to prevent symptomatic venous thromboembolism in hospitalized medical patients. Ann Intern Med 2007;146:278-88.

21. Barbar S, Noventa F, Rossetto V, et al. A risk assessment model for the identification of hospitalized medical patients at risk for venous thromboembolism: the Padua Prediction Score. J Thromb Haemost 2010;8: 2450-7.

22. Scheres LJJ, Brekelmans MPA, Beenen LFM, et al. Sexspecific differences in the presenting location of a first venous thromboembolism. J Thromb Haemost 2017;15: 1344-50.

23. McHugh KB, Visani L, DeRosa M, et al. Gender comparison in pulmonary embolism (results from the International Cooperative Pulmonary Embolism Registry [ICOPER]). Am J Cardiol. 2002;89:616-9.

24. Deng X, Li Y, Zhou L, et al. Gender differences in the symptoms, signs, disease history, lesion position and pathophysiology in patients with pulmonary embolism. PLoS ONE 2015;10:e0133993.

25. Prandoni P, Lensing AWA, Prins MH, et al. Prevalence of pulmonary embolism among patients hospitalized for syncope. N Engl J Med 2016;375:1524-31.

26. Barrios D, Morillo R, Guerassimova I, et al. Sex differences in the characteristics and short-term prognosis of patients presenting with acute symptomatic pulmonary embolism. PLoS ONE 2017;12:e0187648.

27. Ebadi HR, Le Gal G, Carrier R, et al. Differences in clinical presentation of pulmonary embolism in women and men. J Thromb Haemost 2010;8:693-8.

28. Wells PS, Anderson DR, Rodger M, et al. Derivation of a simple clinical model to categorize patients probability of pulmonary embolism: increasing the models utility with the SimpliRED D-dimer. Thromb Haemost. 2000;83:416-20.

29. Prandoni P, Falanga A, Piccioli A. Cancer and venous thromboembolism. Lancet Oncol 2005;6:401-10.

30. Sørensen HT, Sværke C, Farkas DK, et al. Superficial and deep venous thrombosis, pulmonary embolism and subsequent risk of cancer. Eur J Cancer 2012;48:586-93.

31. Douketis JD, Gu C, Piccoli A, et al. The long-term risk of cancer in patients with a first episode of venous thromboembolism. J Thromb Haemost 2009; 7:546-51.

32. Blanco-Molina A, Enea I, Gadelha T, et al. Sex differences in patients receiving anticoagulant therapy for venous thromboembolism. Medicine 2014;93:309-17.

33. Marshall AL, Bartley AC, Ashrani AA, et al. Sex-based disparities in venous thromboembolism outcomes: A National Inpatients Sample (NIS)-based analysis. Vascular Medicine 2017;22:121-27.

34. Khorana AA, Kuderer NM, Culakova E, et al. Development and validation of a predictive model for chemother- 
apy-associated thrombosis. Blood 2008;111:4902-7.

35. Rizkallah J, Man P, Sin DD. Prevalence of pulmonary embolism in acute exacerbations of COPD: A Systematic review and meta-analysis. Chest 2009;135:592-4.

36. Beemath A, Stein PD, Skaf E, et al. Risk of venous thromboembolism in patient hospitalized with heart failure. Am J Cardiol. 2006;98:793-795.

37. Steffen LM, Cushman M, Peacock JM, et al. Metabolic syndrome and risk of venous thromboembolism: Longitudinal Investigation of Thromboembolism Etiology. J Thromb Haemost 2009;7:746-51.

38. ESC Guidelines on the diagnosis and management of acute pulmonary embolism of the ESC.

39. Van Mens TE, van der Pol LM, Van Es N, et al. Sex-specific performance of pre-imaging diagnostic algorithms for pulmonary embolism. J Thromb Haemost 2018;16: 858-65.

40. Vinson DR, Ballard DW, Mark DG et al. Risk stratifyng emergency department patients with acute pulmonary embolism: Does the simplified Pulmonary Embolism Severity Index perform as well as the original? Thrombosis Research 2016;148:1-8.
41. Agarwal S, Donald Clark III, Karan Sud et al. Gender disparities in outcomes and re source utilization for acute pulmonary embolism hospitalizations in the United States. Am J Cardiol 2015;116:1270-1276.

42. Mansour S, Alotaibi G, Wu C, et al. Sex disparities in hospitalization and mortality rates for venous thromboembolism. J Thromb Thrombolysis 2017;44:197-202.

43. Loffredo L, Violi F, Perri L. Sex related differences in patients with acute venous thromboembolism treated with new oral anticoagulants. A meta-analysis of the interventional trials. Int J Cardiology 2016; 212:255-258.

44. Raccah BH, Amichai P, Donna RZ, et al. Gender differences in efficacy and safety of direct oral anticoagulants in atrial fibrillation:systematic review and network meta-analysis. Ann Pharmacotherapy 2018;1-8.

45. Dentali F, Sironi AP, Gianni M, et al. Gender difference in efficacy and safety of nonvitamin $\mathrm{k}$ antagonist oral antocoagulants in patients with nonvalvular atrial fibrillation or venous thromboembolism:a systematic review and a meta-analysis of the literature. Semin Thromb Hemost 2015;41:774-787. 


\title{
Le principali malattie respiratorie in ottica di genere dall'epidemiologia alla diagnosi e alla terapia: versamento pleurico
}

\author{
Carlo Zaninetti, ${ }^{1,2}$ Claudio Tana ${ }^{3}$ \\ ${ }^{1}$ Medicina Generale II, IRCCS Fondazione Policlinico San Matteo e Università degli Studi di Pavia, Pavia; ${ }^{2}$ Dottorato di Ricerca \\ in Medicina Sperimentale, Università di Pavia, Pavia; ${ }^{2}$ UOC di Medicina Interna e Lungodegenza Critica, Azienda Ospedaliero- \\ Universitaria di Parma, Parma, Italia
}

\section{Introduzione}

Il versamento pleurico, definito come eccessivo accumulo di liquido nello spazio pleurico, è una manifestazione patologica di riscontro assai frequente. Stime recenti affermano che colpisca oltre 1,5 milioni di individui all'anno nei soli Stati Uniti d'America. Nella maggior parte dei casi, la causa del versamento pleurico è secondaria allo scompenso cardiaco congestizio, alla polmonite o a neoplasie. ${ }^{1,2}$

L'omeostasi del liquido pleurico poggia su un delicato equilibrio dipendente dal rapporto fra le pressioni idrostatica ed oncotica locali, e dall'efficienza del sistema linfatico. In condizioni di normalità, il liquido entra nello spazio pleurico dal microcircolo capillare - spinto dalla pressione idrostatica - e vi esce per effetto del riassorbimento dei vasi linfatici a livello della pleura parietale. In specifiche condizioni, per lo più patologiche, esso può raggiungere lo spazio pleurico anche dall'interstizio polmonare, dalla pleura viscerale o dalla cavità addominale. In ultima analisi, un incremento del liquido pleurico si può realizzare per aumentata produzione e/o per un inadeguato riassorbimento del medesimo. ${ }^{3}$

La tipologia più frequente di versamento pleurico di natura essudatizia, o infiammatoria, è quella secondaria alla polmonite (versamento parapneumonico), la cui eventuale infezione può configurare il quadro dell'empiema pleurico. Il versamento pleurico maligno, o neoplastico, è la seconda causa più frequente di versamento essudatizio tra i pazienti sottoposti a toracentesi.

Corrispondente: Carlo Zaninetti, Medicina Generale II, IRCCS Fondazione Policlinico San Matteo e Università degli Studi di Pavia, Pavia, Italia.

Tel.: 0382.502580 - Fax: 0382.526223

E-mail: carlo.zaninetti01@universitadipavia.it

Articolo pubblicato secondo la Creative Commons Attribution NonCommercial 4.0 License (CC BY-NC 4.0).

(C) Copyright C. Zaninetti e C. Tana, 2019

Licensee PAGEPress, Italy

QUADERNI - Italian Journal of Medicine 2019; 7(2):28-31
Le neoplasie che più spesso lo determinano sono il tumore polmonare, il tumore mammario e le malattie linfoproliferative. ${ }^{4}$

Tra le cause maggiori di versamento trasudatizio vi sono invece il già citato scompenso cardiaco, la cirrosi epatica e la sindrome nefrosica. ${ }^{2}$ Altre cause frequenti di versamento pleurico sono riassunte nella Tabella 1. Indipendentemente dalla sua natura, la presenza del versamento pleurico spesso si associa ad un peggioramento della prognosi della malattia di base e, talora, ad un incremento della mortalità. ${ }^{5-7}$ Pertanto, il riconoscimento tempestivo, l'identificazione dell'eziologia e l'impostazione di un corretto trattamento di questa condizione patologica costituiscono, a tutt'oggi, un capitolo non secondario della pratica clinica quotidiana dell'internista.

La valutazione del paziente con versamento pleurico si è nettamente affinata con l'avvento dell'ecografia point of care, sia per la determinazione quantitativa che qualitativa del versamento stesso. ${ }^{8}$ L'impiego dell'ecografia come guida alla procedura ha inoltre migliorato l'outcome della toracentesi, aumentandone l'efficacia e riducendone le complicanze. ${ }^{9}$

L'analisi chimico-fisica del liquido pleurico è ancor oggi di rilevante importanza nella diagnostica differenziale del versamento. In particolare, la determinazione della natura essudatizia o trasudatizia del versamento per la quale resta sostanzialmente valida l'applicazione dei criteri di Light (definizione della natura infiammatoria del versamento in presenza di un rapporto liquido pleurico/siero della concentrazione di proteine $>0,5 \mathrm{o}$ di un rapporto liquido pleurico/siero della concentrazione di LDH $>0,6$ o della sola concentrazione di LDH nel liquido pleurico $>200 \mathrm{UI}$ ) costituisce il primo passo dell'inquadramento diagnostico. ${ }^{1,10}$

La terapia del versamento pleurico varia notevolmente in base alla natura e all'entità del versamento e, soprattutto, al suo impatto sul quadro clinico globale del paziente. Esso può limitarsi a presidi medici (antibiotici, diuretici, ossigeno-terapia) o richiedere l'impiego di procedure di drenaggio. Specialmente nel caso del versamento neoplastico condizionante dispnea, trovano applicazione anche il posizionamento di cateteri tunnellizzati e la pleurodesi mediante talcaggio., ${ }^{1,11}$ 


\section{Il versamento pleurico nell'ottica di genere}

Il versamento pleurico è una manifestazione patologica che si riscontra in svariate condizioni cliniche comuni ad entrambi i sessi - seppure con prevalenza di genere talora differente (come avviene ad esempio nell'ipertensione polmonare, nella tromboembolia polmonare e nelle collagenopatie) - ed anche in alcune patologie appannaggio del solo sesso femminile. E' il caso della Sindrome di Meigs, rappresentata, nella sua forma classica, dall'associazione di idrotorace e versamento ascitico a neoplasia ovarica benigna, della Sindrome da iperstimolazione ovarica e dell'endometriosi. Tralasciando queste ultime, che costituiscono del resto un prezioso laboratorio per la ricerca di possibili determinanti di genere del versamento pleurico in corso di patologie comuni - basti pensare alle molecole secrete dall'ovaio, il cui ruolo patogenetico nel versamento pleurico è stato ben descritto nella Sindrome da iperstimolazione ovarica $^{12}$ - ci concentreremo sulle evidenze della letteratura relative alle differenze di genere del versamento pleurico in condizioni cliniche di sostanziale uguale riscontro fra i sessi.

\section{Versamento pleurico trasudatizio}

Un recente studio promosso dalla Società Spagnola di Medicina Interna ha preso in esame il versamento pleurico nel contesto dello scompenso cardiaco acuto. ${ }^{13}$ Lo scopo dell'analisi, condotta su 3245 pazienti ricoverati in reparti di medicina interna, era quello di determinarne la prevalenza, le caratteristiche cliniche e le implicazioni prognostiche. Il versamento era presente nel $46 \%$ dei soggetti (1546). In più della metà dei casi $(58 \%)$ il versamento era bilaterale; quando monolaterale, la sede destra era maggiormente interessata della sinistra (27 vs 14\%). Ad un'analisi univariata, il sesso maschile è risultato significativamente associato alla presenza di versamento pleurico $(\mathrm{P}<0,01)$. Altri predittori di versamento erano la sindrome coronarica acuta, i valori di BMI, di creatinina, di BNP e di NT-proBNP, le pressioni polmonari e il grado di compromissione della frazione di eiezione del ventricolo sinistro. Il sesso maschile - insieme a valori di pressioni polmonari $>55 \mathrm{mmHg}$, di NTproBNP $>3500 \mathrm{pg} / \mathrm{mL}$ e di prealbumina $<15 \mathrm{mg} / \mathrm{L}$ - è inoltre risultato associato in modo indipendente al versamento pleurico (analisi multivariata).

I risultati di questo studio sottolineano per la prima volta un possibile ruolo del sesso maschile nel determinare la comparsa del versamento pleurico nell'ambito dello scompenso cardiaco acuto. Ulteriori indagini sono necessarie per la conferma di questa associazione; va segnalato, infatti, che precedenti analisi condotte su simili casistiche di minore numerosità avevano riportato una maggiore prevalenza di versamento pleurico nello scompenso cardiaco in individui di sesso femminile, di età avanzata e ad alto grado di comorbilità. ${ }^{14,15}$ Ulteriori studi potranno inoltre far luce sulle possibili cause di questa associazione, che al momento sono materia di sole ipotesi. Tra queste, il possibile ruolo di fattori meccanici legati al genere maschile (conformazione e fisiologia della gabbia toracica, del diaframma e dello scavo pleurico) oppure ormonali, con possibili effetti sul microcircolo e/o sul sistema linfatico della pleura parietale.

Il sesso maschile potrebbe inoltre influire sulla formazione di versamento pleurico favorendo uno sviluppo precoce, rispetto al sesso femminile, di insufficienza cardiaca destra. E' stata infatti riportata,

Tabella 1. Principali cause di versamento pleurico trasudatizio ed essudatizio. ${ }^{1-5}$

\begin{tabular}{|c|c|}
\hline Versamento pleurico trasudatizio & Versamento pleurico essudatizio \\
\hline $\begin{array}{l}\text { Cause più comuni: } \\
\text { - Cirrosi epatica } \\
\text { - Scompenso cardiaco congestizio } \\
\text { - Sindrome nefrosica }\end{array}$ & $\begin{array}{l}\text { Cause più comuni: } \\
\text { - Infezioni batteriche (es. versamento parapneumonico), virali, fungine, da TBC, da parassiti } \\
\text { - Tumori primitivi (es. mesotelioma pleurico) e metastatici (es. mammella, ovaio, polmone) }\end{array}$ \\
\hline $\begin{array}{l}\text { Altre cause: } \\
\text { - Ipoalbuminemia } \\
\text { - Glomerulonefrite } \\
\text { - Embolia polmonare } \\
\text { - Ipertensione polmonare } \\
\text { - Sarcoidosi } \\
\text { - Sindrome del polmone coartato } \\
\text { - Atelettasia } \\
\text { - Sindrome della vena cava superiore } \\
\text { - Mixedema } \\
\text { - Pericardiopatie } \\
\text { - Urinotorace } \\
\text { - Shunt ventricolo-peritoneale } \\
\text { Dialisi peritoneale }\end{array}$ & $\begin{array}{l}\text { Altre cause: } \\
\text { - Forme reattive a condizioni infiammatorie (es. forma parapneumonica e postattinica) } \\
\text { - Infarto miocardico } \\
\text { - Sindrome da iperstimolazione ovarica } \\
\text { - Sindrome di Meigs } \\
\text { - Colecistite } \\
\text { - Pancreatite } \\
\text { - Ascesso epatico/splenico } \\
\text { - Artrite reumatoide } \\
\text { - Lupus eritematoso sistemico } \\
\text { - Sarcoidosi } \\
\text { - Emotorace/chilotorace } \\
\text { - Da farmaci (es. amiodarone, metotrexato, fenitoina, beta-bloccanti, interleuchina-2, clozapina) }\end{array}$ \\
\hline
\end{tabular}


seppure in un diverso setting di pazienti, affetti da ipertensione polmonare, un'associazione tra questa condizione isolata e lo sviluppo di versamento pleurico. ${ }^{16}$

\section{Versamento pleurico essudatizio}

A differenza del tipo trasudatizio, il versamento pleurico essudatizio vede di per sé un numero maggiore di eziologie, con meccanismi fisiopatologici quasi del tutto differenti. Vi è inoltre una certa variabilità di genere in base alla patologia responsabile del versamento, che rende conto in parte anche della differente prevalenza delle differenti tipologie nella popolazione generale.

In particolare, il versamento pleurico di tipo essudatizio viene causato più frequentemente da lesioni di natura eteroplastica (soprattutto del polmone) ed infezioni di vario genere (batteriche, virali, fungine, meno spesso parassitarie e da malattia tubercolare) (vedi Tabella 1 per le principali cause di versamento essudatizio).

I versamenti paraneoplastici costituiscono il 57\% di tutti i versamenti di tipo essudatizio. Le cause possono essere molteplici, e presentano una eziologia variabile in base al sesso. Nei soggetti di sesso femminile il tumore polmonare e a seguire mammario prevalgono rispetto alle altre cause, mentre nei soggetti di sesso maschile la neoplasia polmonare, prostatica ed altre forme neoplastiche come il linfoma prevalgono in misura superiore. ${ }^{17}$ In genere, il versamento paraneoplastico presenta una prevalenza maggiore nei soggetti di sesso femminile rispetto al maschile, ${ }^{18}$ rispettivamente polmonare $(44,4 \%)$, mammario $(24,4 \%)$ e mesotelioma (12,2\%). La sopravvivenza globale in genere è molto bassa (11 mesi, range $0,5-$ 55) e inficiata in misura significativa da fattori prognostici quali il sottotipo istologico e lo stadio della neoplasia $(\mathrm{P}=0,008)$, il peso specifico $(\mathrm{P}<0,001)$, la presenza di neutrofilia $(\mathrm{P}=0,018)$ ed il rapporto neutrofili/linfociti $(\mathrm{P}=0,002) .{ }^{18}$

In un altro studio, Das ha confermato recentemente la maggior prevalenza di versamento paraneoplastico nel sesso femminile (31 donne su 47 pazienti, 66\%), e ha evidenziato come sia più frequente nei soggetti di età adulta ed avanzata ( $\geq 60$ anni, $38,3 \%$ ), laddove invece vi sembra essere una maggior prevalenza di versamento ad eziologia tubercolare nei giovani con determinati fattori di rischio ( $<40$ anni, $76,6 \%) .{ }^{19}$

$\mathrm{Al}$ di là delle cause infettive, vi è inoltre una spiccata differenza di genere anche nelle forme autoimmunitarie e reumatiche in genere. In particolare, le manifestazioni pleuropolmonari nel lupus eritematoso sistemico presenterebbero una maggior incidenza nei soggetti di sesso femminile (rapporto F:M 10:1), manifestandosi con pleurite lupica nel $50 \%$ delle donne affette, e caratteristicamente da versamento e dolore di tipo pleuritico. Il versamento solitamente risulta bi- laterale, talvolta unilaterale. ${ }^{20} \mathrm{Al}$ contrario, nell'artrite reumatoide l'interessamento pleuropolmonare ha una maggior prevalenza nel sesso maschile, con rapporto M:F 2:1, una età di insorgenza tra i 50 e 60 anni ed una maggior incidenza nei pazienti fumatori rispetto ai non fumatori. ${ }^{21}$

\section{Conclusioni}

Il versamento pleurico è una manifestazione di frequente riscontro nella pratica clinica dell'internista e può accompagnare diverse condizioni patologiche, delle quali spesso condiziona la prognosi negativamente.

L'analisi chimico-fisica del liquido pleurico, con la conseguente definizione di essudato o trasudato, costituisce tuttora uno strumento fondamentale nella diagnostica differenziale del versamento pleurico.

L'epidemiologia del versamento pleurico in corso di patologie comuni - come il versamento pleurico secondario a scompenso cardiaco o il versamento neoplastico - suggerisce la presenza di fattori promuoventi correlati al genere.

\section{Bibliografia}

1. Feller-Kopman D, Light R. Pleural Disease. N Engl J Med. 2018 Feb 22;378(8):740-751.

2. Light R. Pleural disease. $6^{\text {th }}$ ed. Philadelphia: Lippincott Williams \& Wilkins, 2013.

3. Noppen M, De Waele M, Li R, Gucht KV, D'Haese J, Gerlo E, Vincken W. Volume and cellular content of normal pleural fluid in humans examined by pleural lavage. Am J Respir Crit Care Med. 2000 Sep;162(3 Pt 1):1023-6.

4. Taghizadeh N, Fortin M, Tremblay A. US Hospitalizations for Malignant Pleural Effusions: Data From the 2012 National Inpatient Sample. Chest. 2017 Apr;151(4): 845-854.

5. Walker SP, Morley AJ, Stadon L, De Fonseka D, Arnold DT, Medford ARL, Maskell NA. Nonmalignant Pleural Effusions: A Prospective Study of 356 Consecutive Unselected Patients. Chest. 2017 May;151(5):1099-1105.

6. Postmus PE, Brambilla E, Chansky K, Crowley J, Goldstraw P, Patz EF Jr, Yokomise H. International Association for the Study of Lung Cancer International Staging Committee; Cancer Research and Biostatistics; Observers to the Committee; Participating Institutions. The IASLC Lung Cancer Staging Project: proposals for revision of the $\mathrm{M}$ descriptors in the forthcoming (seventh) edition of the TNMclassification of lung cancer. J Thorac Oncol. 2007 Aug;2(8):686-93.

7. Clive AO, Kahan BC, Hooper CE, Bhatnagar R, Morley AJ, Zahan-Evans N, Bintcliffe OJ, Boshuizen RC, Fysh ET, Tobin CL, Medford AR, Harvey JE, van den Heuvel MM, Lee YC, Maskell NA. Predicting survival in malignant pleural effusion: development and validation of the LENT prognostic score. Thorax. 2014 Dec;69(12): 1098-104.

8. Yang PC, Luh KT, Chang DB, Wu HD, Yu CJ, Kuo SH. 
Value of sonography in determining the nature of pleural effusion: analysis of 320 cases. AJR Am J Roentgenol. 1992 Jul;159(1):29-33.

9. Diacon AH, Brutsche MH, Solèr M. Accuracy of pleural puncture sites: a prospective comparison of clinical examination with ultrasound. Chest. 2003 Feb;123(2): 436-41.

10. Light RW, Macgregor MI, Luchsinger PC, Ball WC Jr. Pleural effusions: the diagnostic separation of transudates and exudates. Ann Intern Med. 1972 Oct;77(4): 507-13.

11. Roberts ME, Neville E, Berrisford RG, Antunes G, Ali NJ; BTS Pleural Disease Guideline Group. Management of a malignant pleural effusion: British Thoracic Society Pleural Disease Guideline 2010. Thorax. 2010 Aug;65 Supp12:ii32-40.

12. Namavar Jahromi B, Parsanezhad ME, Shomali Z, Bakhshai P, Alborzi M, Moin Vaziri N, Anvar Z. Ovarian Hyperstimulation Syndrome: ANarrative Review of Its Pathophysiology, Risk Factors, Prevention, Classification, and Management. Iran J Med Sci. 2018 May;43 (3):248-260.

13. Morales-Rull JL, Bielsa S, Conde-Martel A, AramburuBodas O, Llàcer P, Quesada MA, Suárez-Pedreira I, Manzano L, Barquero MM, Porcel JM. RICA Investigators group. Pleural effusions in acute decompensated heart failure: Prevalence and prognostic implications. Eur J InternMed. 2018 Jun;52:49-53.

14. Trullàs JC, Formiga F, Montero M, Conde A, Casado J,
Carrasco FJ, Díez J, Ceresuela LM. Grupo RICA. [Paradox of obesity in heart failure: results from the Spanish RICA Registry]. Med Clin (Barc). 2011 Dec 10;137 (15):671-7.

15. Kataoka H. Ultrasound pleural effusion sign as a useful marker for identifying heart failure worsening in established heart failure patients during follow-up. Congest Heart Fail. 2012 Sep-Oct;18(5):272-7.

16. Brixey AG, Light RW. Pleural effusions occurring with right heart failure. CurrOpinPulm Med. 2011 Jul;17(4): 226-31.

17. Ogunleye EO, et al. Aetiology and Demographic Attributes of Common Pleural Collections in an African Population. Surgical Science. 2013.47066.

18. Anevlavis S, Kouliatsis G, Sotiriou I, Koukourakis MI, Archontogeorgis K, Karpathiou G, Giatromanolaki A, Froudarakis ME. Prognostic factors in patients presenting with pleural effusion revealing malignancy. Respiration. 2014;87(4):311-6.

19. Das DK. Age and sex distribution in malignant and tuberculous serous effusions: A study of 127 patients and review of the literature. GeriatrGerontol Int. 2015 Sep;15(9):1143-50.

20. Keane MP, Lynch JP $3^{\text {rd }}$. Pleuropulmonary manifestations of systemic lupus erythematosus. Thorax. 2000 Feb;55(2):159-66.

21. Shaw M, Collins BF, Ho LA, Raghu G. Rheumatoid arthritis-associated lungdisease. Eur Respir Rev. 2015 Mar;24(135):1-16. 


\title{
Come una società scientifica può diffondere la cultura di genere?
}

\author{
Paola Gnerre, ${ }^{1}$ Cecilia Politi, ${ }^{2}$ Andrea Fontanella ${ }^{3}$ \\ ${ }^{1}$ Medicina 2, Ospedale San Paolo, Savona; ${ }^{2}$ Medicina Interna, PO “F. Veneziale", Isernia; ${ }^{3}$ Dipartimento di Medicina, \\ Ospedale del Buon Consiglio-Fatebenefratelli, Napoli, Italia
}

Numerosi studi hanno dimostrato come le sequenze fisiopatologiche e la psicologia tra uomini e donne siano differenti e come questa diversità abbia un profondo impatto sullo sviluppo, sulla diagnosi e sul trattamento della malattia. Gli uomini e le donne pur essendo esposti alle medesime patologie, presentano sintomi, progressione di malattie e risposta ai trattamenti molto diversi tra loro. Storicamente, i termini sesso e genere sono stati usati in modo intercambiabile spesso anche dai professionisti sanitari, ma oggi le loro accezioni sono e devono diventare sempre più distinte. Secondo la definizione della WHO, il termine gender designa i molti e complessi modi in cui le differenze tra i sessi acquisiscono significato e diventano fattori strutturali nell'organizzazione della vita sociale. Il termine genere indica quindi la percezione che ogni individuo ha di se stesso come maschio o femmina (identità di genere) e il sistema socialmente costruito intorno a quelle identità (ruolo di genere). Il termine sesso indica invece solo la dimensione corporea di una persona, riferendosi, pertanto, alle diversità biologiche tra maschi e femmine, come i genitali e le differenze genetiche. L'uguaglianza di genere si basa sul principio fondamentale del rispetto della dignità della persona da attuarsi attraverso l'applicazione della parità di trattamento tra gli individui da qui la necessità di inserire questa visione di genere in tutte le aree mediche. L'articolo 3 del DDL Lorenzin, di recente approvazione, garantisce per la prima volta in Italia la qualità e l'appropriatezza delle prestazioni erogate dal SSN basate sulle differenze derivanti dal sesso e dal genere. Diventa pertanto imprescindibile realizzare

Corrispondente: Paola Gnerre, Dipartimento di Medicina Interna, Ospedale San Paolo, Savona, Italia.

Tel.: +39.019.8404358 - Fax: +39.019 .8404583 .

E-mail:pgnerre@yahoo.it

Articolo pubblicato secondo la Creative Commons Attribution NonCommercial 4.0 License (CC BY-NC 4.0).

CCopyright P. Gnerre et al., 2019

Licensee PAGEPress, Italy

QUADERNI - Italian Journal of Medicine 2019; 7(2):32-33 politiche formative per la diffusione della medicina di genere tra gli operatori sanitari. Questo può essere realizzato attraverso l'attività formativa promossa ai propri iscritti dalle Società Scientifiche e dagli Ordini dei Medici, nonché formando alla visione di genere $\mathrm{i}$ nuovi professionisti della salute già nel percorso accademico universitario, sia della laurea magistrale che delle specializzazioni.

La Società Scientifica FADOI da tempo ha abbracciato una politica di diffusione della medicina di genere tra i suoi iscritti. Da oltre 10 anni Cecilia Politi, esperta nazionale del settore, è la referente dell'Area di medicina di genere FADOI e sin dal 2012 è presente una sessione di medicina di genere all'interno del congresso Nazionale o, comunque, inserendo un argomento dedicato al genere nei vari corsi del Congresso.

In questi ultimi anni la formazione ha particolarmente coinvolto alcuni giovani FADOI con l'obiettivo di orientare, fin dall'inizio dell'attività lavorativa, alla cultura delle diversità in medicina. Tre giovani dottoresse, sponsorizzate direttamente dalla Società, hanno partecipato al Master di Medicina di Genere promosso da FADOI. Ai giovani FADOI sotto la guida esperta della Professoressa Politi è stato dato il mandato di realizzare la sessione di medicina di genere durante il Convegno Nazionale e alcuni giovani hanno partecipato alla stesura di alcune review sulle differenze di genere focalizzandosi sulle aree di maggior competenza internistica come l'area cardio-vascolare, metabolica e respiratoria.

Gli obiettivi di FADOI dei prossimi anni saranno di accrescere progressivamente la cultura e la formazione di genere tra i suoi iscritti, collaborando con l'Istituto Superiore della Sanità allo scopo di garantire la diffusione della medicina di genere all'interno del Sistema Sanitario Nazionale e in particolare nell'area internistica.

A tale scopo i vertici della Società hanno concordato anche attraverso il VADEMECUM sulla medicina di genere di: i) promuovere l'attività scientifica $\mathrm{e}$ di ricerca della Società includendo sempre un'ottica di genere contribuendo a garantire dati scientifici e statistici per la dimensione del genere; ii) sviluppare attività di prevenzione $\mathrm{e}$ di individuazione dei fattori di rischio genere-specifici per le principali patologie di interesse internistico; iii) garantire sempre un'equa di- 
stribuzione di uomini e donne nei trials clinici promossi dalla Società; iv) sviluppare percorsi di diagnosi e cura definiti e orientati al genere; v) includere sempre nell'offerta formativa rivolta agli iscritti una visione di genere. In Tabella 1 sono declinate nello specifico alcune delle attività di ricerca e formazione promosse dalla Società Scientifica FADOI per diffondere la cultura di genere.

Attraverso la stretta collaborazione con la Società Scientifica ANÍMO degli infermieri di Medicina Interna questa cultura di genere potrà essere estesa anche al comparto infermieristico.

La medicina di genere non è la medicina delle donne ma è la medicina della persona che studia l'influenza del sesso e del genere sulla fisiopatologia e la clinica delle malattie. Un approccio di genere permette al professionista sanitario di riconoscere come le differenze nel rischio di sviluppare una malattia, nonché nel decorso e nella risposta alle cure (gender effect), influenzi in modo significativo gli snodi decisionali diagnostici e terapeutici. Il sesso in molti casi è il fattore di rischio principale per una data malattia. In conclusione il ruolo del sesso e del genere deve essere necessariamente preso in considerazione nella ricerca e nell'assistenza sanitaria ma per far sì che ciò accada è necessario che le Società Scientifiche e la formazione Accademica si impegnino a diffondere una cultura di genere. Non farlo potrà solo avere influenze negative sulla salute dei cittadini, sull'appropriatezza delle cure e sulla sopravvivenza dei nostri stessi pazienti.

Tabella 1. Attività promosse dalla Società Scientifica FADOI per incrementare una cultura di genere (Vademecum).

Creazione di programmi di prevenzione cardiovascolare a lungo termine, specificamente adattati per le donne

Supportare programmi di prevenzione primaria e secondaria delle malattie cardiovascolari

Considerare le differenze specifiche per sesso nella diagnostica e nella terapia delle più comuni patologie internistiche

Considerare le differenze sesso-specifiche nella formazione dei professionisti sanitari

Realizzare strategie di trattamento ottimizzate sensibili al genere in malattie cardiovascolari potenzialmente letali rivolte agli operatori e ai professionisti sanitari

Inclusione delle possibili differenze di sesso e genere nelle domande di ricerca e nella progettazione della ricerca

Descrizione dei risultati della ricerca in un modo sensibile al genere 


\section{LINEE GUIDA PER GLI AUTORI}

I Quaderni dell 'Italian Journal of Medicine (Quaderni ITJM), costituiscono una collana supplementare solo online annessa alla rivista Italian Journal of Medicine contenente lavori solo in lingua italiana.

I Quaderni ITJM pubblicano:

- Monografie ad hoc individuate dal Presidente FADOI, dal Consiglio Direttivo, dal Board Scientifico o dall'Editor in Chief dell'Italian Journal of Medicine, in funzione del contesto scientifico-istituzionale attuale.

- Monografie ad hoc su temi di particolare rilevanza scientifica a cura della Commissione FADOI Giovani.

- Traduzioni in italiano di alcuni lavori pubblicati sui numeri standard dell'Italian Journal of Medicine, di particolare interesse per la comunità scientifica.

\section{STESURA DEI LAVORI}

I lavori dovranno essere redatti in modo conforme alle linee guida sotto riportate:

- I manoscritti devono essere scritti interamente in lingua italiana, su documento di Word, con carattere Times New Roman/Arial, dimensione 12, formato A4, interlinea doppia e margini $2,54 \mathrm{~cm}$

Parole totali: $\max$ 4000; Sommario/Abstract: $\max 250$ parole; Bibliografia: min 40 voci; Tabelle e Figure: $3 / 5$ totali (le tabelle non devono superare n. 1 pagina del documento in Word).

- La strutturazione del contenuto deve attenersi agli standard internazionali per la Rassegna (Review): i) Abstract riassuntivo dell'intero lavoro; ii) Introduzione al tema trattato; iii) Criteri e strumenti di ricerca (criteri di inclusione/esclusione, banche dati consultate, ...); iv) i successivi paragrafi devono illustrare le più recenti scoperte scientifiche nel settore; v) Conclusioni; vi) Bibliografia.

- La prima pagina deve riportare: i) titolo (in stampatello minuscolo), senza acronimi; ii) nome e cognome per esteso di ciascun autore; iii) affiliazione(i) di ciascun autore, numerate con numeri arabi iv) eventuali ringraziamenti; v) nome e indirizzo postale completi dell'autore corrispondente, corredati da telefono, fax, e-mail; vi) da 3 a 5 parole chiave, separate da virgola. La seconda pagina può riportare: i) contributi degli autori, e.g. informazioni relative a contributi sostanziali delle persone coinvolte nello studio (http://www.icmje.org/\#author); ii) dichiarazione relativa a potenziali conflitti d'interesse; iii) ulteriori informazioni (e.g. fondi, esposizioni durante conferenze...).

- In caso di utilizzo di tabelle, queste devono essere tutte numerate con numeri arabi e citate nel testo in ordine consecutivo (e.g. NON nominare le tabelle come Tabella $1 \mathrm{~A}, 1 \mathrm{~B}, \ldots$ o $1.0,1.1, \ldots$ ). Le tabelle devono essere presentate in formato editabile. Ciascuna tabella deve essere corredata da una breve didascalia; in caso di abbreviazioni, riportare una nota a piè di CIASCUNA tabella che spieghi TUTTE le abbreviazioni presenti in ognuna.

- In caso di utilizzo di figure, queste devono essere inviate in formato tiff o .jpg, allegate al manoscritto in singoli files, secondo le seguenti specifiche:

i) a colori (salvate in modalità CMYK): minimo 300 dpi di risoluzione;

ii) in bianco e nero: minimo $600 \mathrm{dpi}$ di risoluzione;

iii) minimo $17,5 \mathrm{~cm}$ di larghezza.

Ciascuna figura deve essere corredata da una breve didascalia.

$N B$ : In caso di Tabelle/Figure riprese e/o modificate da altri lavori già pubblicati, sarà cura degli autori accertarsi se tali materiali siano o meno coperti da copyright e procurarsi i permessi necessari per la riproduzione. Tali permessi dovranno essere allegati alla versione definitiva del lavoro. L'ufficio editoriale si riserva la facoltà di rimuovere Tabelle/Figure coperte da copyright, se sprovviste dei necessari permessi.

- In caso di utilizzo di abbreviazioni, la prima volta che esse sono citate è necessario scrivere per esteso la definizione+abbreviazione tra parentesi tonde [e.g. risonanza magnetica $(\mathrm{RMN})]$, a seguire si dovrà riportare solo l'abbreviazione (unica eccezione: nei titoli e nelle didascalie di tabelle e figure NON si utilizzano abbreviazioni).

\section{BIBLIOGRAFIA}

Le voci bibliografiche devono essere formattate secondo lo stile Vancouver.

Nella sezione Bibliografia, le voci bibliografiche devono essere numerate consecutivamente nell'ordine in cui appaiono per la prima volta nel testo (NON in ordine alfabetico) e, nel testo, devono essere indicate con numeri arabi in apice. Voci bibliografiche riferite a comunicazioni personali o dati non pubblicati devono essere incorporate nel testo e NON inserite tra le voci numerate [e.g. (Wright 2011, dati non pubblicati) o (Wright 2011, comunicazione personale)]. Le voci bibliografiche nella sezione Bibliografia devono tassativamente essere preparate come segue:

i) più di 3 autori, citare 3 autori, et al. Se il lavoro contiene solo 4 autori, citarli tutti e 4 ;

ii) titolo del lavoro in stampatello minuscolo;

iii) nome della rivista, senza punti, abbreviato secondo gli standard internazionali; in caso di dubbi sulla corretta abbreviazione, fare riferimento ai seguenti siti:

a. ISI Journal Abbreviations Index (http://library.caltech.edu/ reference/abbreviations/);

b. Biological Journals and Abbreviations (http://home.ncifcrf. gov/research/bja/);

c. Medline List of Journal Titles (ftp://ftp.ncbi.nih.gov/pubmed/J_Medline.txt);

iv) inserire l'anno di pubblicazione subito dopo il nome della rivista, seguito da punto e virgola;

v) NON inserire giorno o mese di pubblicazione;

vi) citare solo il volume, seguito dai due punti (NON citare il fascicolo tra parentesi);

vii) abbreviare le pagine, e.g. 351-8

Per accertarsi di aver correttamente formattato le voci bibliografiche, confrontarle con le citazioni in PubMed (http://www.ncbi. nlm.nih.gov/pubmed).

Esempi (prestare attenzione anche alla punteggiatura):

Articolo standard su Rivista

Halpern SD, Ubel PA, Caplan AL. Solid-organ transplantation in HIV-infected patients. N Engl J Med 2002;347:284-7.

Proceedings

Christensen S, Oppacher F. An analysis of Koza's computational effort statistic for genetic programming. In: Foster JA, Lutton E, Miller J, Ryan C, Tettamanzi AG, eds. Genetic programming. EuroGP 2002: Proceedings of the 5th European Conference on Genetic Programming, 2002 Apr 3-5, Kinsdale, Ireland. Berlin: Springer; 2002. pp 182-91.

Articoli i cui autori sono Organizzazioni

Diabetes Prevention Program Research Group. Hypertension, insulin, and proinsulin in participants with impaired glucose tolerance. Hypertension 2002;40:679-86.

Libri

Murray PR, Rosenthal KS, Kobayashi GS, Pfaller MA. Medical microbiology. 4th ed. St. Louis, MO: Mosby; 2002. (CITAZIONE DEL LIBRO INTERO)

Meltzer PS, Kallioniemi A, Trent JM. Chromosome alterations in human solid tumors. In: Vogelstein B, Kinzler KW, eds. The genetic basis of human cancer. New York, NY: McGraw-Hill; 2002. pp 93113. (CITAZIONE DI UN CAPITOLO)

\section{MODALITÀ D'INVIO DEI LAVORI}

Monografie

Gli Autori dovranno fare riferimento all'Editor-in-Chief o alle persone da lui designate nelle lettere di invito a scrivere gli articoli programmati.

Per gli articoli inviati da giovani internisti, gli Autori dovranno fare riferimento alla Dr.ssa Paola Gnerre (e-mail: pgnerre@yahoo.it) e agli eventuali altri referenti da lei designati, nelle prime fasi di stesura dei manoscritti, revisioni e correzioni. 


\section{QUADERNI}

dell'Italian Journal

of Medicine

La Dr.ssa Gnerre raccoglierà poi le versioni definitive dei lavori di ciascuna monografia e provvederà all'invio di tutti i materiali all'ufficio editoriale.

I lavori solo nella loro versione definitiva e approvata dalla Commissione FADOI Giovani dovranno pervenire all'ufficio editoriale già pronti per l'impaginazione e immediata pubblicazione (già corredati da eventuali permessi per la riproduzione di tabelle e immagini redatti secondo le presenti linee guida).

Traduzioni

Previo invito dell'Editor-in-Chief, gli Autori dovranno far pervenire all'ufficio editoriale la versione tradotta in italiano, al seguente indirizzo e-mail: paola.granata@pagepress.org

Il file in formato Word dovrà essere formattato secondo gli standard editoriali della rivista ufficiale ed essere già pronto per impagina- zione e immediata pubblicazione (corredato da eventuali permessi per la riproduzione di tabelle e immagini).

Si prega di inviare le eventuali tabelle in formato editabile e le figure in alta definizione secondo gli standard sopra riportati.

\section{NOTA PER GLI AUTORI}

I lavori pubblicati sui Quaderni ITJM non verranno indicizzati, ma saranno liberamente disponibili in un'apposita sezione del sito FADOI (http://www.fadoi.org/) e della rivista ufficiale.

Gli Autori i cui lavori siano accettati per la pubblicazione sui Quaderni ITJM e che fossero interessati a vederli pubblicati anche sulla rivista ufficiale, dovranno sottomettere attraverso il sito dell'ITJM (www.italjmed.org) la versione (già tradotta) in inglese e redatta in modo conforme alle linee guida della rivista; seguiranno poi la procedura di selezione tramite peer review e, se accettati, saranno inseriti nel piano editoriale standard.

\section{STAFF EDITORIALE}

Paola Granata, Journal Manager

paola.granata@pagepress.org

Claudia Castellano, Production Editor

Tiziano Taccini, Technical Support
PUBBLICATO DA

PAGEPress Publications

via A. Cavagna Sangiuliani 5

27100 Pavia, Italy

T. +39.0382 .464340$

F: +39.0382 .34872$

\section{agepress}

www.pagepress.org info@pagepress.org

\section{QUADERNI - ITALIAN JOURNAL OF MEDICINE}

Tutti gli articoli pubblicati sui QUADERNI - Italian Journal of Medicine sono redatti sotto la responsabilità degli Autori. La pubblicazione o la ristampa degli articoli della rivista deve essere autorizzata per iscritto dall'editore. Ai sensi dell'art. 13 del D.Lgs 196/03, i dati di tutti i lettori saranno trattati sia manualmente, sia con strumenti informatici e saranno utilizzati per l'invio di questa e di altre pubblicazioni e di materiale informativo e promozionale. Le modalità di trattamento saranno conformi a quanto previsto dall'art. 11 del D.Lgs 196/03. I dati potranno essere comunicati a soggetti con i quali PAGEPress intrattiene rapporti contrattuali necessari per l'invio delle copie della rivista. Il titolare del trattamento dei dati è PAGEPress Srl, via A. Cavagna Sangiuliani $5-27100$ Pavia, al quale il lettore si potrà rivolgere per chiedere l'aggiornamento, l'integrazione, la cancellazione e ogni altra operazione di cui all'art. 7 del D.Lgs 196/03.

https://www.italjmed.org/index.php/ijm/quad 
PAGEPress - Scientific Publications

Via A. Cavagna Sangiuliani, 5 - 27100 Pavia - Italy

Phone +390382 464340 - Fax +390382 34872

www.pagepress.org 